\title{
OPTIMIZATION OF GENERALIZED ORDER-LEVEL INVENTORY SYSTEM UNDER FULLY PERMISSIBLE DELAY IN PAYMENT
}

\author{
Bappa Mondal ${ }^{1}$, Arindam Garai ${ }^{2, *}$ And TAPAn Kumar RoY ${ }^{1}$
}

\begin{abstract}
This article presents one generalized order-level inventory system with fully permissible delay in payment in various trade-credit intervals. Review of existing literature finds few EOQ models under simultaneous considerations of time-dependent generalized demand rate, time-dependent generalized rate of deterioration and time-dependent generalized backordering under fully permissible delay in payment. In those existing studies, the optimal inventory depletion time is independent of demand over the entire cycle. Here, present article frames one generalized order-level inventory system with fully permissible delay in payment across various trade-credit intervals. This finds that when the trade-credit period is longer than the inventory depletion time to settle the account, the optimal inventory depletion time is dependent of demand. Under this ambiance, one particular case having time-dependent ramp type demand rate, two variables time-dependent Weibull distribution rate of deterioration and timedependent backordering rate with fully permissible delay in payment, finds that the optimal inventory depletion time varies inversely over demand in that period. Moreover, the proposed model shrinks to obtain many well-established EOQ models as the special cases to it. Next, a general algorithm determines the various optimal solutions corresponding to seven cases. The managerial insights extracted from sensitivity analysis of parameters include the suggestion to halt the promotional activities so as to foreshorten the demand in shortage period. Also, this analysis attests that the longer waiting period of retailers should be counterbalanced with various promotional activities and anticipated benefits.
\end{abstract}

Mathematics Subject Classification. 90B05, 90B06.

Received March 3, 2019. Accepted August 25, 2019.

\section{INTRODUCTION}

Inventory management is essential to any contemporary and complex organization. Properly managed inventories pay back through many ways, including monetary profits and enduring relationships with customers. As well, the interweave connections among these various purposes of businesses retain the splendiferous prominence of inventory management. Whereas the classical Economic Order Quantity (EOQ) model by Harris [20] and associated variants [69] are widespread, current business practices include highly fluctuating demand, perishability and deterioration for seasonal products, shortage, trade-credit period and so on. Consequently, the

Keywords. Generalized order-level inventory, ramp type demand rate, Weibull distribution deterioration rate, partial backorder, delay in payment.

1 Department of Mathematics, Indian Institute of Engineering Science and Technology, Shibpur, Howrah, India.

2 Department of Mathematics, Sonarpur Mahavidyalaya, Kolkata, W.B., India.

*Corresponding author: fuzzy_arindam@yahoo.com 
relatively unpretentious conditions in classical inventory models fail to cope with recent business criteria in numerous real-life based cases. One single major aspect to the decision-maker (DM) concerning the inventory and production activities is to measure and to control the fluctuating demands [60], such as linear demand $[14,31]$, stock-dependent demand [40], time-dependent demand [42] and price-dependent demand [12]. Over the years, researchers studied several more varieties of consumption tendencies, like quadratic demand $[25,26]$, exponential demand [17], time and price-dependent demand [45] and stock and price-dependent demand [33]. In addition, present-day business practices involve dealing with highly complex demand structures that comprise the quality sensitive demand [38], backordered dependent demand [63], shortages and selling price-dependent demand [37] and all that. Again, the quality and quantity of products with a short lifetime, like food items, pharmaceuticals, chemicals and cut flowers deteriorate over time due to decay, obsolescence, perishability etc. Deteriorating products engulf $50 \%$ of retail industry in North America and $30 \%$ of supermarket sales all over the world [6]. The grocery stores in USA encounter more than 30 billion losses due to deterioration in each year [15]. Accordingly, in order to tackle with the fluctuating demand and the deterioration of products, very many enterprises have modified the pricing strategies in recent years. One more common factor of inventory management models are the shortages of products. Owing to the prolonged waiting time for products, some customers change their purchase plan and leave. Whereas this is reasonable due to highly competitive market scenarios and today's fast-paced life, many others are willing to be patient until the fulfillment of demand. Below, one can find several well-established studies from existing research articles on inventory.

- Historically, Silver and Meal [60] first suggested a simple modification of EOQ model to consider varying demand.

- Ghare and Schrader [17] were the first to consider consequences of deterioration of items in inventory model.

- Covert and Philip [10] derived an EOQ formula of inventory model for deteriorating items with twoparameter Weibull distribution rate of deterioration under conditions of constant demand, instantaneous delivery and without shortage. When the deterioration was minuscule, they could reduce the model to one non-deteriorating EOQ model, and when the deterioration was exponential in nature, they could reduce model to an existing model of Ghare and Schrader [17].

- Mandal and Pal [32] discussed deterministic and probabilistic demand situations in an order-level inventory system of deteriorating items with ramp type demand rate. They presented several key managerial insights through in-depth sensitivity analysis.

- Papachristos and Skouri [41] studied a continuous review inventory model over a finite-planning horizon with deterministic varying demand and constant deterioration rate. They considered shortages that were partially backordered and varied exponentially with time.

- In an EOQ model for items with Weibull distribution deterioration, ramp type demand rate and partial backordering by $\mathrm{Wu}$ [70], the optimal solution was unique and independent of demand rate. In case of exponential distribution deterioration, this model reduced to model of Mandal and Pal [32]. Also, the nonlinear Weibull distribution deterioration yielded more preferable optimal solution than constant or linear case.

- Wu et al. [71] developed the necessary and sufficient conditions for existence and uniqueness of optimal solution to an EOQ model for non-instantaneous deteriorating items with stock-dependent demand. Here, they allowed shortages besides the variable and time-dependent backordering rate for next replenishment. Moreover, they identified the best circumstance based on minimum total relevant cost per unit time.

- Skouri et al. [64] considered an inventory model with general ramp type demand rate, Weibull deterioration rate and partial backordering to unsatisfied demand. Here, the replenishment policies of model depended on shortages. Also, they considered ramp type demand rate up to stabilization time along with the backordering rate as a non-increasing function of waiting time up to next replenishment.

- Sarkar et al. [53] developed an EOQ model for finite production rate and for deteriorating items with timedependent increasing demand. Here, they considered component cost and selling price at continuous rate of time. Moreover, they optimized the number of orders over finite-planning horizon. 
- Sarkar et al. [51] energetically reviewed the Economic Production Quantity (EPQ) model with rework process at a single-stage manufacturing system with planned backorders. They developed three different inventory models corresponding to three different distribution density functions, viz. uniform, triangular, and beta. Their analytical derivation could provide a closed-form solution to inventory models.

- Tayyab and Sarkar [67] presented an EPQ model with an imperfect multi-stage production system by considering a random defective rate in a cleaner multi-stage lean manufacturing system. They observed that continuous improvements in production process reliability could reduce the proportion of defective items by performing various lean manufacturing techniques and thus this could enlist total productive maintenance at the highest rank.

- Kim and Sarkar $[27,48]$ considered a complex multi-stage imperfect manufacturing process to clean the production system and thereby investigated through a stochastic inventory model with budget constraint for simultaneously optimizing number of shipments, replenishment interval, safety factor, backorder discounts, quality factor and lead time as decision variables. Here, they presented two theorems and thereby analytically obtained global optimum solution to this model.

- Pando et al. [39] analyzed an inventory model for deteriorating items with stock-dependent demand rate by considering non-linear holding cost in both time and stock level with constant rate of deterioration per unit time. They found that the optimal cycle time and optimal lot size were always greater than the optimal values with minimum inventory cost per unit time.

- Qiu et al. [43] considered a real-world variant of Production Routing Problems (PRP) with perishable inventory. They analyzed the optimal integrated decisions on deliverables and sold products with varying manufacturing periods. Also, this article strengthened lot-sizing and lifted Miller-Tucker-Zemlin subtour elimination constraints to PRP with perishable inventory.

- Sarkar [49] presented one analytical approach to manage defective items in a multi-stage production system. Here, the author employed Lagrangian method to obtain the global minimum cost.

- Mahmodi [31] considered selling of substitutable and deteriorating products having price-dependent linear demand. This article analytically showed the existence and uniqueness of nash equilibrium prices. Moreover, it presented several interesting insights on pricing and inventory decisions of competing agents.

- San-Jose et al. [46] determined the lot size and the length of inventory cycle in order to maximize total profit per unit time to one inventory model. This article allowed shortages in model and presented a sequential optimization procedure to determine the optimal policy.

In addition, Sarkar et al. [54] studied EOQ models with variable setup cost and carbon emission cost. Moon et al. [36] presented the min-max distribution-free model having service level constraints and variable lead time. On the other hand, the trade-credit or delay in payment strategy facilitates the purchase of goods and services without immediate payment. Sometimes, suppliers offer a certain delay in making payments to retailers so as to insist on buying more items. The extensive review of existing literature finds much attentions on different trade-credit policies in inventory models. Some notable contributions in this area of research are as follows:

- Historically, Goyal [19] first studied inventory models with fully permissible delay in payments to settle the ordered amount. The numerical illustrations in this article showed how permissible delay in settling the replenishment account could significantly decrease the economic replenishment interval and subsequently the cost.

- Shinn et al. [59] extended models by Goyal [19]. They found that a retailer benefiting from offer by suppliers for permissible delay in payments, could expect more profit arising due to the stimulated demand on lower retail price.

- Jamal et al. [24] determined the optimal ordering policy for deteriorating items under permissible delay in payment and allowable shortage. This model reduced to that with no shortage when the backorder cost was extremely high. In case, delay in payment was longer than the period needed to deplete inventory in each cycle, the order quantity varied inversely with permissible delay in payment. 
- Chang and Dye [5] used a varying deterioration rate and the condition of permissible delay in payments in conjunction with EOQ model. In addition, the shortages within the model were neither completely backordered nor completely lost, as they assumed backordering rate to be inversely proportional to waiting time of next replenishment.

- Min et al. [34] presented an EPQ model for deteriorating items with inventory level dependent demand and permissible delay in payment. In this article, they deduced several existing optimal solutions as special cases to that model.

- Sarkar [47] dealt with an EOQ model for finite replenishment rate with time-dependent demand and deterioration. Here, he considered a trade-credit offer by suppliers for retailers, in order to buy more items with different discount rates on purchasing costs. In this model, the retailers could earn more by selling their products during the credit period.

- Taleizadeh and Nematollahi [65] investigated the effects of time value of money and inflation on optimal ordering policy in inventory control system and thereby proposed an EOQ model to manage perishable items over finite time horizon planning under delay in payment.

- Jaggi et al. [23] considered an EOQ model, where retailers could earn interest on revenue generated after fulfilling the outstanding demand as soon as new consignment arrived in beginning of cycle. Here, they simultaneously optimized the cycle length and stock-in period.

- Based on a sample of 3383 groups of public US firms from a novel database, Seifert et al. [55] found that their available data were consistent with the causal relations and theoretical predictions of operations management literature. Here, they found how long payment delays could be sub-optimal.

- Rajan and Uthayakumar [44] determined the optimal replenishment schedule of an EOQ inventory model with promotional efforts and backordering under delay in payments. Here, they mathematically showed the existence of unique optimal replenishment schedule and thereby determined the optimal solution through an iterative algorithm.

- Pal [38] considered a production inventory system with allowable delay in payments. Here, the quality of products depended on demand structures of markets. In case, manufacturers could not pay the due amount to suppliers within credit period, the author deliberated two alternative approaches.

- Ghandehari and Dezhtaherian [16] presented an EOQ model for deteriorating items with partial backordering and financial considerations. In order to minimize total cost of the inventory system, they considered partially backordered shortages in the finite-planning horizon and then developed an exact algorithm.

In addition, Chu et al. [8] and Chung et al. [9] also extended the model of Goyal [19] for deteriorating items. Many researchers like Li et al. and Taleizadeh et al. $[29,66]$ developed inventory model by considering permissible delay in payment. Recently, Diabat et al., Jaggi et al. and Lashgari et al. $[13,22,28]$ developed a more general EOQ model with delay in payments, price-discount effect and different types of demand rate. Researchers such as Hung [21] extended the inventory model of Skouri et al. [64] with ramp type demand rate and Weibull deterioration rate to arbitrary demand rate and arbitrary deterioration rate. In addition, for case of partial backorder, Hung [21] found how any attempt to tackle the targeted inventory models under ramp type or any other types of demand rate became redundant for finite time horizon and subsequently determined optimal policy in closed-form. This approach could dramatically simplify the solution procedure. Next, Lin [30] considered general type demand rate, general type rate of deterioration yet a specific partial backordering and then determined closed-form optimal solution. Das et al. [11] considered the defective item dependent stochastic credit period in their inventory model. Here, the credit period offered by manufacturers depended on defective ratio of items and the lead time demand followed normal distribution. However, in that article, the demand, deterioration and backorder were not of general type. Also, Shi et al. [58] could determine the optimal ordering policies for single deteriorating item with ramp type demand rate. Besides, Table 1 covers several other recent and well-established articles in this area of research.

Along with all above existing studies that centered around various types of demand and deterioration rates, the present article considers the general type demand and general type deterioration with general type partial backorder along with various scenarios of fully permissible delay in payment. The aim of this article is to 
OPTIMIZATION OF INVENTORY SYSTEM UNDER DELAY IN PAYMENT

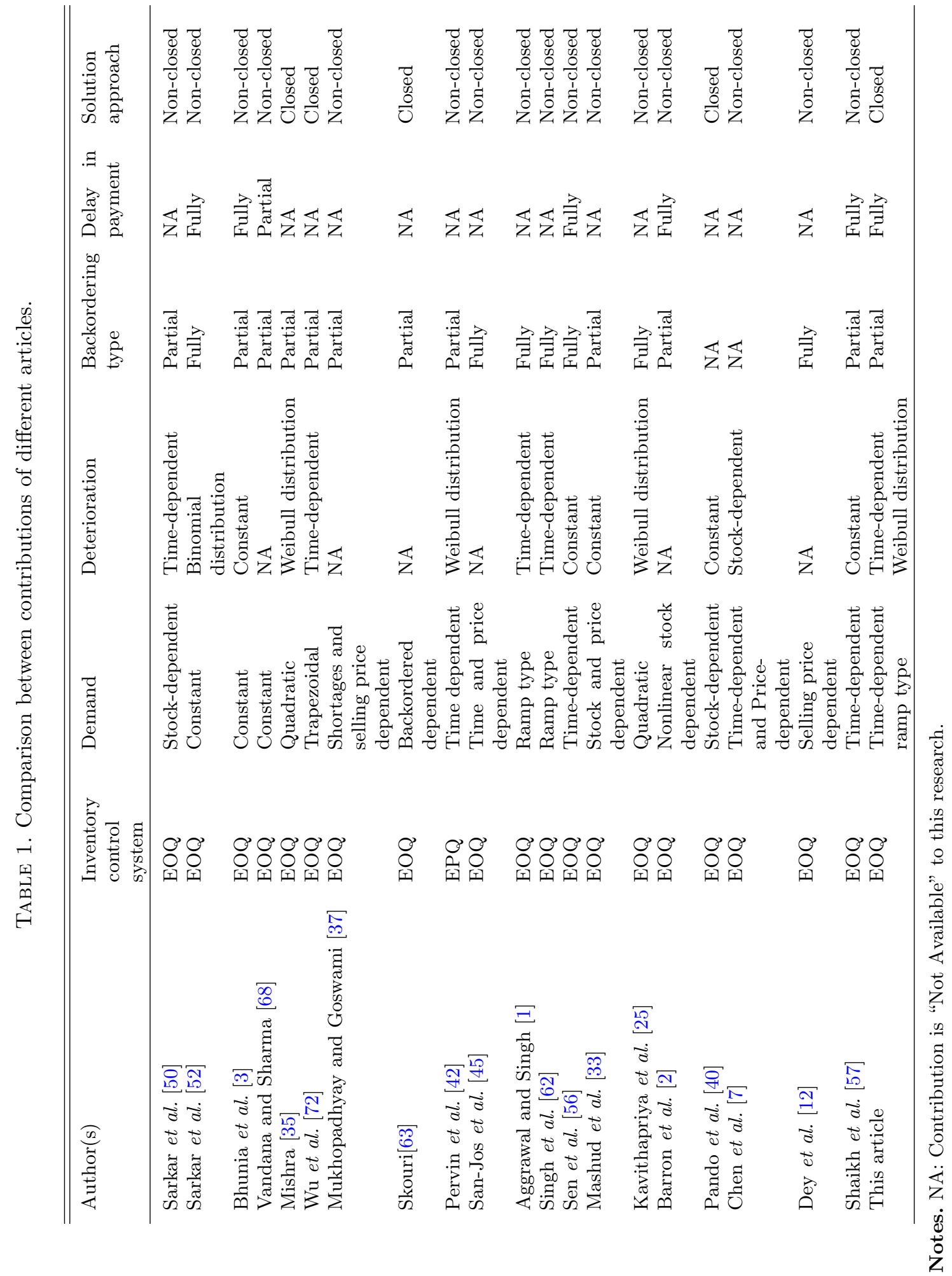


determine the closed-form optimal cost to proposed model. To the best of present knowledge, no existing research article considers the delay in payment, which has turned out to be much beneficial to enterprises in recent times, along with general type demand rate, general type deterioration rate and general type partial backorder.

While considering all these factors into account, the major contributions to fill in existing research gaps are as follows

- To formulate a closed-form EOQ model with general type demand rate, general type rate of deterioration and general type partial backorder along with fully permissible delay in payment in various trade-credit intervals.

- To present one particular case within proposed model by considering time-dependent ramp type demand function, time-dependent Weibull distribution rate of deterioration and partial backorder under fully permissible delay in payment.

- To shorten the proposed model into various well-established EOQ models under specific considerations.

- To perform the sensitivity analysis to parameters of proposed model and subsequent presentation of key managerial insights.

The organization of the rest of this article is as follows. Section 2 illustrates the problem definition, symbols with descriptions and hypotheses to proposed model. Section 3 formulates the mathematical model of generalized order-level inventory system with fully permissible delay in payment in various trade-credit intervals. Section 4 describes a particular form of proposed model and converts the proposed model to several existing models under specific considerations. Next, Section 5 introduces one general algorithm to determine the optimal solution to proposed model from highly non-linear relations. Then, Section 6 illustrates the proposed model numerically in various trade-credit intervals. Section 7 performs sensitivity analysis of key parameters to various scenarios of proposed model and thereby presents the key managerial insights. Besides, this section suggested several areas of possible application to proposed model. Finally, a list of future scopes of research is in Section 8 .

\section{Problem definition, symbols And hypotheses}

The problem definition, symbols with their descriptions and hypotheses to proposed deterministic inventory replenishment model are as follows

\subsection{Problem definition}

The aim of this study is to formulate a generalized order-level inventory system with fully permissible delay in payment in various trade-credit intervals. Accordingly, the present study deliberates on an inventory model with time-dependent generalized demand rate, time-dependent generalized rate of deterioration, time-dependent generalized backordering under consideration of fully permissible delay in payment. This article considers two sub-cases that are based on settlement time of account, like Case 1. when credit period is shorter than or equal to the inventory depletion time for settling account, and Case 2. when credit period is longer than the inventory depletion time for settling account. Whereas many well-established articles find the optimal inventory depletion time to inventory models to be independent of demand and thus unique at all times [30,70]; present study shows how the optimal inventory depletion time is independent of demand in Case 1, and this depends on demand in Case 2. Evidently, this demonstration steps against the common belief that finds no need to divide the entire period into several sub-intervals of time [21,30]. Under this impression, a particular case with timedependent ramp type demand rate, two variables time-dependent Weibull distribution rate of deterioration and backordering rate in consideration of fully permissible delay in payment results in the same inferences. Moreover, one can deduce various existing EOQ models as the special cases to proposed mathematical model. Evidently, the proposed generalized integrated inventory model has the potential to look right as well as viable to numerous organizations. 


\subsection{Symbols with descriptions}

The symbols along with their descriptions to proposed model are as follows

Decision variables

$t_{1}$

Inventory depletion time (year).

Parameters

$C_{1}$

$C_{2}$

$C_{3}$

$C_{4}$

$\mu$

$\sigma$

$c$

$p$

A

$T$

$I(t)$

$\theta(t)$

$D(t)$

$I_{p}$

$I_{e}$

$S$

$Q$

TAC

Inventory holding cost $(\mathrm{HC})$ per unit item per unit time $(\$ /$ unit item/year).

Shortage Cost (SC) per unit item per unit time (\$/unit item/year).

Deterioration Cost (DC) of unit item (\$/unit item).

Opportunity cost due to Lost-Sales (LS) per unit item (\$/unit item).

Time parameter to time-dependent ramp type demand rate function (year).

Pre-determined permissible period of delay in settling accounts with supplier (year).

Unit purchase cost per unit item (\$/unit item).

Unit selling price per unit item $(\$ /$ unit item).

Replenishment cost (\$/unit item).

Fixed length of time of each ordering cycle (year).

Inventory level at time t over $[0, T]$ (units of item).

Rate of deterioration to time-dependent on-hand inventory over $\left[0, t_{1}\right]$ (unit item).

Non-negative demand rate function (unit item/year).

Percentage of interest to be paid per unit time by retailer $(\$ /$ year).

Percentage of interest to be earned per unit time by retailer $(\$ /$ year$)$.

Initial on-hand inventory level (i.e., $I(0)=S$ ) (unit item).

Order quantity per cycle (unit item).

Total average cost that consists of holding cost, deterioration cost, shortage cost, lost-sales cost, interest paying and interest earned cost $(\$ /$ unit item).

\subsection{Hypotheses}

The hypotheses to the proposed model are as follows

(1) This article allows shortages, which are partially backordered. Here, the backorder function $\lambda(t)$ is decreasing in $t$ and the function $t \lambda(t)$ is increasing in $t$ under the boundary conditions:

$$
\lambda(0)=1, \lambda(T) \geq 0 \text { and } 0 \leq \lambda(t) \leq 1
$$

In addition, this articles presumes that the following relation holds at any time $t$ over cycle $[0, T]$ so as to ensure the existence of optimal solution to it (see for instance, $[21,72]$ )

$$
\lambda(t)+t \lambda^{\prime}(t) \geq 0
$$

(2) This article assumes that retailers receive fully permissible delay in payment within the period $[0, \sigma]$. Again, they earn interest at rate $I_{e}$ in $\left[\sigma, t_{1}\right]$. However, after fixed settlement period $[0, \sigma]$, retailers fully pay back the amount along with interests at rate $I_{p}$. Evidently, $I_{p}>I_{e}$ (see for instance, $[5,19,22]$ ).

(3) In real-life, the lead time can be constant [3], variable [52] and stochastic [27] in nature. However, for sake of simplicity alone, this article considers the lead time to be zero (see for instance, $[4,24,47]$ ).

(4) Replenishment rate is instantaneously infinite. However, its size is finite and constant all through the article (see for instance, $[4,23,26]$ ).

(5) The inventory deteriorates continuously in period $\left[0, t_{1}\right]$ at a rate $\theta(t)$ with $0 \leq \theta(t) \leq 1$ (see for instance, $[7,26,58])$. 
(6) This article presumes that the total HC and DC is higher than SC, LS plus IE within the optimal on-hand inventory period $\left[0, t_{1}^{*}\right]$. In other words, the following relationship is satisfied in period $\left[0, t_{1}^{*}\right]$

$$
\frac{C_{1} \mathrm{e}^{\int_{0}^{t_{1}^{*}}} \theta(x) \mathrm{d} x \int_{0}^{t_{1}^{*}} \mathrm{e}^{-\int_{0}^{t} \theta(x) \mathrm{d} x} \mathrm{~d} t+C_{3}\left(\mathrm{e}^{\mathrm{e}_{0}^{t_{1}^{*}} \theta(x) \mathrm{d} x}-1\right)}{\left\{\left(C_{2}\left(T-t_{1}^{*}\right)-C_{4}\right) \lambda\left(T-t_{1}^{*}\right)+C_{4}\right\}+p I_{e} \sigma}>1 .
$$

\section{Formulation OF MATHEMATiCAL MODEL}

This section formulates one mathematical model with generalized order-level inventory system and fully permissible delay in payment in various trade-credit intervals. Whereas the restoration of initial inventory occurs at $t=0$, the inventory level gradually decreases due to demand $D(t)$ and deterioration $\theta(t)$ up to time $t=t_{1}$. At time $t=t_{1}$, the inventory level becomes zero. Here, shortage is allowed and is partially backordered at predetermined rate $\lambda(T-t)$ and occurs throughout the interval $\left[t_{1}, T\right]$. The next replenishment replaces the total number of backordered items. Also, the backorder function $\lambda(t)$ is decreasing function that satisfies the boundary conditions, such as $\lambda(0)=1$ and $\lambda(T) \geq 0$. By integrating all these deliberations, the authors present an instantaneous inventory level $I(t)$ in form of Boundary Value Problem (BVP) at any time $t$ over cycle $[0, T]$ as follows

$$
\begin{aligned}
& \frac{\mathrm{d} I(t)}{\mathrm{d} t}+\theta(t) I(t)=-D(t), \quad \text { if } \quad 0 \leq t \leq t_{1} \\
& \text { and } \quad \frac{\mathrm{d} I(t)}{\mathrm{d} t}=-D(t) \lambda(T-t), \quad \text { if } t_{1} \leq t \leq T
\end{aligned}
$$

with following boundary conditions

$$
\begin{aligned}
I(0) & =\int_{0}^{t_{1}} D(s) \mathrm{e}^{\int_{0}^{s} \theta(x) \mathrm{d} x} \mathrm{~d} s, \\
\text { and } \quad I\left(t_{1}\right) & =0 .
\end{aligned}
$$

By solving above BVP (3.1)-(3.4), the time-dependent on-hand inventory level at any time $t$ at different stocks is as follows

$$
I(t)= \begin{cases}\mathrm{e}^{-\int_{0}^{t} \theta(x) \mathrm{d} x} \int_{t}^{t_{1}} D(s) \mathrm{e}^{\int_{0}^{s} \theta(x) \mathrm{d} x} \mathrm{~d} s, & \forall 0 \leq t \leq t_{1}, \\ -\int_{t_{1}}^{t} D(s) \lambda(T-s) \mathrm{d} s, & \forall t_{1} \leq t \leq T .\end{cases}
$$

To any EOQ model, the order quantity per cycle $[0, T]$ is the sum of initial inventory $(I(0))$ and backordered inventory in period $\left[t_{1}, T\right]$. Here, the equation (3.3) presents $I(0)$ to be $\int_{0}^{t_{1}} D(s) \mathrm{e}_{0}^{s} \theta(x) \mathrm{d} x \mathrm{~d} s$. Also, the equation (3.5) presents the time-dependent backordered inventory to be $\int_{t_{1}}^{t} D(s) \lambda(T-s) \mathrm{d} s$ in period $\left[t_{1}, T\right]$. Therefore, the order quantity per cycle $[0, T]$ is as follows

$$
Q=\int_{0}^{t_{1}} D(s) \mathrm{e}^{\int_{0}^{s} \theta(x) \mathrm{d} x} \mathrm{~d} s+\int_{t_{1}}^{T} D(s) \lambda(T-s) \mathrm{d} s .
$$

Again, after placing the order, managers consider the cost to store ordered products. There has to be a place, a store or a warehouse, which is either owned or rented. There are some costs associated with warehouse, even if this is owned, like insurance cost, taxes, electricity cost, maintenance cost and all that. Consequently, the $\mathrm{HC}$ is directly proportional to the quantity of items in inventory, as well as to the holding period. Here, equation (3.5) 


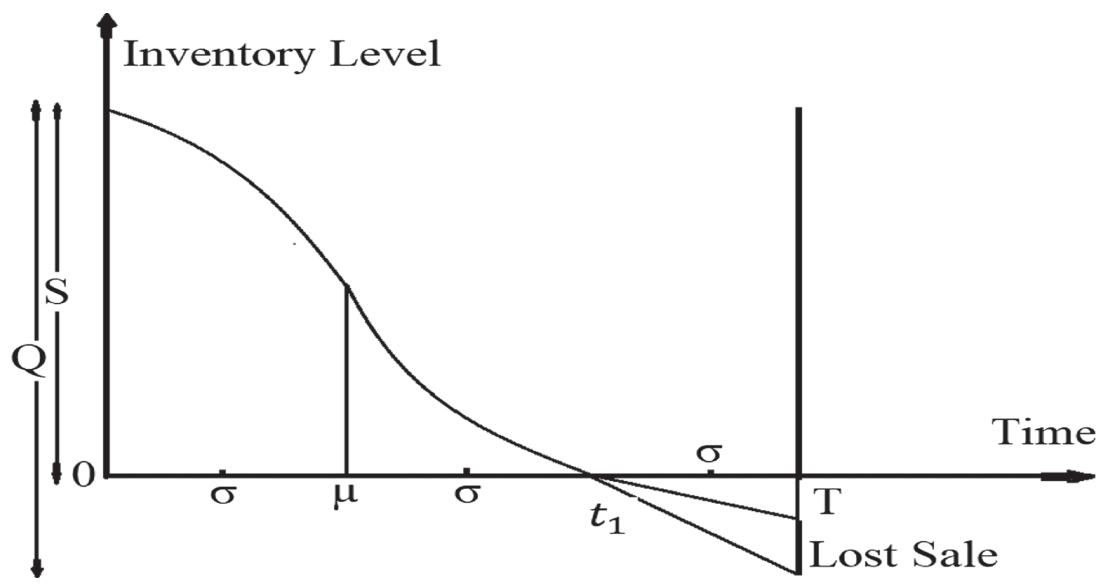

FiguRE 1. Graphical representation of inventory system across various trade-credit periods.

presents the time-dependent on-hand inventory level in period $\left[0, t_{1}\right]$ to be $\mathrm{e}^{-\int_{0}^{t} \theta(x) \mathrm{d} x}\left(\int_{t}^{t_{1}} D(s) \mathrm{e}^{\int_{0}^{s} \theta(x) \mathrm{d} x} \mathrm{~d} s\right)$. Therefore, by presuming $C_{1}$ to be $\mathrm{HC}$ per unit time, the total HC per cycle $[0, T]$ is as follows

$$
\mathrm{HC}=C_{1} \int_{0}^{t_{1}} \mathrm{e}^{-\int_{0}^{t} \theta(x) \mathrm{d} x}\left(\int_{t}^{t_{1}} D(s) \mathrm{e}^{\int_{0}^{s} \theta(x) \mathrm{d} x} \mathrm{~d} s\right) \mathrm{d} t .
$$

In case, the demand from retailers is more than the production rate, the shortages arise. Shortages engrave negative images of managers and thus directly influence the integrated profit of organizations. In Figure 1, one can find shortages in period $\left[t_{1}, T\right]$ to proposed EOQ model. Therefore, the associated SC can be obtained by multiplying the unit SC $\left(C_{2}\right)$ by the total time-dependent backordered inventory $\left(\int_{t_{1}}^{t} D(s) \lambda(T-s) \mathrm{d} s\right)$ per cycle $[0, T]$ is as follows

$$
\mathrm{SC}=C_{2} \int_{t_{1}}^{T} \int_{t_{1}}^{t} D(s) \lambda(T-s) \mathrm{d} s \mathrm{~d} t
$$

Again, real-life businesses involve the items that are damaged, decayed, vaporized or affected by external factors and thus fail to satisfy the demand. The associated DC in period $\left[0, t_{1}\right]$ is proportional to the number of deteriorated items, which is the difference between initial inventory $(I(0))$ obtained from (3.3), and total timedependent demand $(D(s))$ in period $\left[0, t_{1}\right]$. Therefore, by presuming $C_{3}$ to be unit DC, the total DC per cycle $[0, T]$ is as follows

$$
\mathrm{DC}=C_{3} \int_{0}^{t_{1}} D(s)\left(\mathrm{e}^{\int_{0}^{s} \theta(x) \mathrm{d} x}-1\right) \mathrm{d} s
$$

Next, the lost-sales are those selling opportunities that were lost and include the subsequent loss of intangible goodwill. When an item is out of stock, suppliers don't carry some particular brands, or any other reason comes out; the suppliers loose the opportunity to sell. Besides, the cost of lost-sales includes the cost of sharing information with retailers and all that. Therefore, the time-dependent LS at any time $t$ is the difference between total time-dependent demand $D(t)$ in period $\left[t_{1}, T\right]$ and total time-dependent backordered inventory $\int_{t_{1}}^{t} D(t) \lambda(T-s)$ in period $\left[t_{1}, T\right]$. By presuming $C_{4}$ to be unit LS cost, the total LS per cycle $[0, T]$ is as follows

$$
\mathrm{LS}=C_{4} \int_{t_{1}}^{T}[1-\lambda(T-t)] D(t) \mathrm{d} t .
$$

Now, this article considers two cases, which are primarily based on fully permissible delay in payment as follows 


\subsection{Payment before total inventory depletion time $\left(0 \leq \sigma \leq t_{1}\right)$}

The retailers receive fully permissible delay in payment within period $[0, \sigma]$. However, after the fixed settlement period $[0, \sigma]$, retailers fully pay back the money along with interest at rate $I_{p}$. Consequently, the total interest payable to supplier by retailers per cycle $[0, T]$ is as follows

$$
\mathrm{IP}_{1}=c I_{p} \int_{\sigma}^{t_{1}} \mathrm{e}^{-\int_{0}^{t} \theta(s) \mathrm{d} s}\left(\int_{t}^{t_{1}} D(s) \mathrm{e}^{\int_{0}^{s} \theta(x) \mathrm{d} x} \mathrm{~d} s\right) \mathrm{d} t
$$

In addition, retailers earn the interest at a rate $I_{e}$ in period $[0, \sigma]$. Therefore, the total interest earned by retailer per cycle $[0, T]$ is as follows

$$
\mathrm{IE}_{1}=p I_{e} \int_{0}^{\sigma} t D(t) \mathrm{d} t
$$

Hence, the TAC per cycle $[0, T]$ is as follows

$$
\begin{aligned}
\operatorname{TAC}\left(t_{1}\right)= & \frac{1}{T}\left[A+C_{1} \mathrm{HC}+C_{2} \mathrm{SC}+C_{3} \mathrm{DC}+C_{4} \mathrm{LS}+c I_{p} \mathrm{IP}_{1}-p I_{e} \mathrm{IE}_{1}\right] \\
= & \frac{1}{T}\left[A+C_{1} \int_{0}^{t_{1}} \mathrm{e}^{-\int_{0}^{t} \theta(x) \mathrm{d} x}\left(\int_{t}^{t_{1}} D(s) \mathrm{e}^{\int_{0}^{s} \theta(x) \mathrm{d} x} \mathrm{~d} s\right) \mathrm{d} t+C_{2} \int_{t_{1}}^{T} \int_{t_{1}}^{t} D(s) \lambda(T-s) \mathrm{d} s \mathrm{~d} t\right. \\
& +C_{3} \int_{0}^{t_{1}} D(s)\left(\mathrm{e}^{\int_{0}^{s} \theta(x) \mathrm{d} x}-1\right) \mathrm{d} s+C_{4} \int_{t_{1}}^{T}[1-\lambda(T-t)] D(t) \mathrm{d} t \\
& \left.+c I_{p} \int_{\sigma}^{t_{1}} \mathrm{e}^{-\int_{0}^{t} \theta(s) \mathrm{d} s}\left(\int_{t}^{t_{1}} D(s) \mathrm{e}^{\int_{0}^{s} \theta(x) \mathrm{d} x} \mathrm{~d} s\right) \mathrm{d} t-p I_{e} \int_{0}^{\sigma} t D(t) \mathrm{d} t\right] .
\end{aligned}
$$

The first and second order differential quotients of $\operatorname{TAC}\left(t_{1}\right)$ with respect to $t_{1}$ are as follows

$$
\begin{aligned}
\frac{\mathrm{dTAC}\left(t_{1}\right)}{\mathrm{d} t_{1}}= & \frac{D\left(t_{1}\right)}{T}\left[C_{1} \mathrm{e}^{\int_{0}^{t_{1}} \theta(x) \mathrm{d} x} \int_{0}^{t_{1}} \mathrm{e}^{-\int_{0}^{t} \theta(x) \mathrm{d} x} \mathrm{~d} t+C_{3}\left(\mathrm{e}^{\int_{0}^{t_{1}} \theta(x) \mathrm{d} x}-1\right)-\left\{\left(C_{2}\left(T-t_{1}\right)-C_{4}\right)\right.\right. \\
& \left.\left.\times \lambda\left(T-t_{1}\right)+C_{4}\right\}+c I_{p} \mathrm{e}^{\int_{0}^{t_{1}} \theta(x) \mathrm{d} x} \int_{\sigma}^{t_{1}} \mathrm{e}^{-\int_{0}^{t} \theta(x) \mathrm{d} x} \mathrm{~d} t\right] .
\end{aligned}
$$

Motivated by equation (3.14), these authors assume one auxiliary function, say $f\left(t_{1}\right)$, as follows

$$
\begin{aligned}
f\left(t_{1}\right)= & C_{1} \mathrm{e}^{\int_{0}^{t_{1}} \theta(x) \mathrm{d} x} \int_{0}^{t_{1}} \mathrm{e}^{-\int_{0}^{t} \theta(x) \mathrm{d} x} \mathrm{~d} t+C_{3}\left(\mathrm{e}^{\int_{0}^{t_{1}} \theta(x) \mathrm{d} x}-1\right)-\left\{\left(C_{2}\left(T-t_{1}\right)-C_{4}\right) \lambda\left(T-t_{1}\right)+C_{4}\right\} \\
& +c I_{p} \mathrm{e}^{\int_{0}^{t_{1}} \theta(x) \mathrm{d} x} \int_{\sigma}^{t_{1}} \mathrm{e}^{-\int_{0}^{t} \theta(x) \mathrm{d} x} \mathrm{~d} t
\end{aligned}
$$

and

$$
\begin{aligned}
\frac{\mathrm{d} f\left(t_{1}\right)}{\mathrm{d} t_{1}}= & C_{1}\left\{1+\theta\left(t_{1}\right) \mathrm{e}^{\int_{0}^{t_{1}} \theta(x) \mathrm{d} x} \int_{0}^{t_{1}} \mathrm{e}^{-\int_{0}^{t} \theta(x) \mathrm{d} x} \mathrm{~d} t\right\}+C_{3} \theta\left(t_{1}\right) \mathrm{e}^{\int_{0}^{t_{1}} \theta(x) \mathrm{d} x}+C_{2}\left\{\lambda\left(T-t_{1}\right)+\left(T-t_{1}\right)\right. \\
& \left.\times \lambda^{\prime}\left(T-t_{1}\right)\right\}+C_{4}\left(-\lambda^{\prime}\left(T-t_{1}\right)\right)+c I_{p}\left\{1+\theta\left(t_{1}\right) \mathrm{e}^{\int_{0}^{t_{1}} \theta(x) \mathrm{d} x} \int_{\sigma}^{t_{1}} \mathrm{e}^{-\int_{0}^{t} \theta(x) \mathrm{d} x} \mathrm{~d} t\right\} .
\end{aligned}
$$

In order to determine optimal value $t_{1}^{*}\left(*\right.$ : denotes optimality) to proposed model (3.13) in $0 \leq t_{1} \leq T$, firstly, hypothesis (3) yields following relation

$$
\lambda^{\prime}\left(T-t_{1}^{*}\right) \geq 0 \text { and } \lambda\left(T-t_{1}^{*}\right)+\left(T-t_{1}^{*}\right) \lambda^{\prime}\left(T-t_{1}^{*}\right) \geq 0 .
$$


Since $\frac{\mathrm{d}^{2} \mathrm{TAC}\left(t_{1}\right)}{\mathrm{d} t_{1}^{2}}=\frac{D\left(t_{1}\right)}{T} \frac{\mathrm{d} f\left(t_{1}\right)}{\mathrm{d} t_{1}}$ and thus all components of expression $\frac{\mathrm{d}^{2} \mathrm{TAC}\left(t_{1}\right)}{\mathrm{d} t_{1}}$ are positive, the expression $\frac{\mathrm{d}^{2} \mathrm{TAC}\left(t_{1}\right)}{\mathrm{d} t_{1}^{2}}$ is positive in $0 \leq t_{1} \leq T$. Also, $t_{1}^{*}$ that minimizes TAC, satisfies the following relation

$$
\begin{aligned}
& C_{1} \mathrm{e}^{\int_{0}^{t_{1}^{*}} \theta(x) \mathrm{d} x} \int_{0}^{t_{1}^{*}} \mathrm{e}^{-\int_{0}^{t} \theta(x) \mathrm{d} x} \mathrm{~d} t+C_{3}\left(\mathrm{e}^{\int_{0}^{t_{1}^{*}} \theta(x) \mathrm{d} x}-1\right)-\left\{\left(C_{2}\left(T-t_{1}^{*}\right)-C_{4}\right) \lambda\left(T-t_{1}^{*}\right)+C_{4}\right\} \\
& +c I_{p} \mathrm{e}^{t_{0}^{t_{1}^{*}} \theta(x) \mathrm{d} x} \int_{\sigma}^{t_{1}^{*}} \mathrm{e}^{-\int_{0}^{t} \theta(x) \mathrm{d} x} \mathrm{~d} t=0 .
\end{aligned}
$$

\subsection{Payment after total inventory depletion time $\left(t_{1} \leq \sigma \leq T\right)$}

In this case, total interest payable in $[0, T]$ is nil i.e., $\mathrm{IP}_{2}=0$. Also, retailer has accumulated fund in various ways, like by selling items, by earning interest in positive inventory period $\left[0, t_{1}\right]$ or by investing cash in period $\left[t_{1}, \sigma\right]$ after exhausting inventory at time $t_{1}$. So, total interest earned in $[0, T]$ is as follows

$$
\mathrm{IE}_{2}=p I_{e}\left(\int_{0}^{t_{1}} t D(t) \mathrm{d} t+\left(\sigma-t_{1}\right) \int_{0}^{t_{1}} D(t) \mathrm{d} t\right)
$$

Analogous to previous case, the TAC per cycle $[0, T]$ is as follows

$$
\begin{aligned}
\operatorname{TAC}\left(t_{1}\right)= & \frac{1}{T}\left[A+C_{1} \mathrm{HC}+C_{2} \mathrm{SC}+C_{3} \mathrm{DC}+C_{4} \mathrm{LS}-p I_{e} \mathrm{IE}_{2}\right] \\
= & \frac{1}{T}\left[A+C_{1} \int_{0}^{t_{1}} \mathrm{e}^{-\int_{0}^{t} \theta(x) \mathrm{d} x}\left(\int_{t}^{t_{1}} D(s) \mathrm{e}^{\int_{0}^{s} \theta(x) \mathrm{d} x} \mathrm{~d} s\right) \mathrm{d} t+C_{3} \int_{0}^{t_{1}} D(s)\left(\mathrm{e}^{\int_{0}^{s} \theta(x) \mathrm{d} x}-1\right) \mathrm{d} s\right. \\
& +C_{2} \int_{t_{1}}^{T} \int_{t_{1}}^{t} D(s) \lambda(T-s) \mathrm{d} s \mathrm{~d} t+C_{4} \int_{t_{1}}^{T}[1-\lambda(T-t)] D(t) \mathrm{d} t-p I_{e}\left\{\int_{0}^{t_{1}} t D(t) \mathrm{d} t\right. \\
& \left.\left.+\left(\sigma-t_{1}\right) \int_{0}^{t_{1}} D(t) \mathrm{d} t\right\}\right] .
\end{aligned}
$$

Hence, this article determines the values of $t_{1}^{*}$ and corresponding $\mathrm{TAC}^{*}$ (see Appendix A) from following relation

$$
\begin{aligned}
& D\left(t_{1}^{*}\right)\left[C_{1} \mathrm{e}^{\int_{0}^{t_{1}^{*}} \theta(x) \mathrm{d} x} \int_{0}^{t_{1}^{*}} \mathrm{e}^{-\int_{0}^{t} \theta(x) \mathrm{d} x} \mathrm{~d} t+C_{3}\left(\mathrm{e}^{\int_{0}^{t_{1}^{*}} \theta(x) \mathrm{d} x}-1\right)-\left\{\left(C_{2}\left(T-t_{1}^{*}\right)-C_{4}\right) \lambda\left(T-t_{1}^{*}\right)+C_{4}\right\}\right. \\
& \left.-p I_{e} \sigma\right]+p I_{e} \int_{0}^{t_{1}^{*}} D(t) \mathrm{d} t=0
\end{aligned}
$$

Therefore, to proposed EOQ model under consideration of delay in payment, the optimal inventory depletion time is dependent on demand for longer credit period than inventory depletion time of settling the account.

\section{Specific CONSIDERATIONS OF PROposed MODEL}

\subsection{One particular case across various trade-credit periods}

In order to synchronize the outcomes of proposed model in Section 3 with recent focuses of enterprises, this section presents one particular case.

Whereas the reviews of existing literature find the EOQ models under various considerations like ramp type demand rate function, Weibull distribution rate of deterioration and partial backorder; to the best of present knowledge, there is not a single study to simultaneously consider all these components under fully permissible 
delay in payment. Here, this sub-section considers all those specific considerations, and thereby reduces the proposed model.

Here, the time-dependent demand function with ramp type demand rate is as follows [32]

$$
D(t)=a+b[t-(t-\mu) H(t-\mu)], \text { where } a, b>0 \text { and } H(t-\mu)= \begin{cases}1 & \text { if } t \geq \mu, \\ 0 & \text { if } t<\mu .\end{cases}
$$

Also, time-dependent Weibull distribution rate of deterioration is defined as $\theta(t)=\alpha \beta t^{\beta-1} ; \alpha, \beta, t>0$. In case, $\beta<1$, the deterioration is decreasing in $t$. In case, $\beta>1$, the deterioration is increasing in $t . \theta(t)$ is constant at $\beta=1[70]$.

When all demands in period $\left[t_{1}, T\right]$ are backordered with a backorder rate defined as $\frac{1}{1+\delta(T-t)}$, also by considering $\delta$ as non-negative backordering parameter, the time-dependent ramp type demand function increases linearly up to the turning point $\mu$ and becomes constant afterwards within the replenishment time. Consequently, it seems rational to sub-divide the time interval in Case 3.1 into two sub-intervals. Accordingly, the timedependent on-hand inventory level of different stocks at any time $t$ is as follows [64]

$$
I(t)= \begin{cases}\mathrm{e}^{-\alpha t^{\beta}}\left[\int_{t}^{\mu}(a+b s) \mathrm{e}^{\alpha s^{\beta}} \mathrm{d} s+\int_{\mu}^{t_{1}}(a+b \mu) \mathrm{e}^{\alpha s^{\beta}} \mathrm{d} s\right] & \text { if } \quad 0 \leq t \leq \mu, \\ \mathrm{e}^{-\alpha t^{\beta}} \int_{t}^{t_{1}}(a+b \mu) \mathrm{e}^{\alpha s^{\beta}} \mathrm{d} s & \text { if } \mu \leq t \leq t_{1} . \\ -\int_{t_{1}}^{t} \frac{(a+b \mu)}{1+\delta(T-s)} \mathrm{d} s & \text { if } t_{1} \leq t \leq T .\end{cases}
$$

Analogous to equation (3.3), the initial inventory can be obtained from equation (4.2) by setting $t=0$ as follows

$$
S=\int_{0}^{\mu}(a+b s) \mathrm{e}^{\alpha s^{\beta}} \mathrm{d} s+\int_{\mu}^{t_{1}}(a+b \mu) \mathrm{e}^{\alpha s^{\beta}} \mathrm{d} s .
$$

Besides, equation (4.2) presents the time-dependent backordered inventory to be $\int_{t_{1}}^{t} \frac{(a+b \mu)}{1+\delta(T-s)} \mathrm{d} s$ in period $\left[t_{1}, T\right]$. Therefore, the order quantity $Q$ per cycle $[0, T]$, analogous to equation (3.6) is as follows

$$
Q=\int_{0}^{\mu}(a+b s) \mathrm{e}^{\alpha s^{\beta}} \mathrm{d} s+\int_{\mu}^{t_{1}}(a+b \mu) \mathrm{e}^{\alpha s^{\beta}} \mathrm{d} s+\int_{t_{1}}^{T} \frac{(a+b \mu)}{1+\delta(T-s)} \mathrm{d} s .
$$

Analogous to equation (3.7), equation (4.2) presents the time-dependent on-hand inventory level in period $[0, \mu]$ to be $\mathrm{e}^{-\alpha t^{\beta}}\left[\int_{t}^{\mu}(a+b s) \mathrm{e}^{\alpha s^{\beta}} \mathrm{d} s+\int_{\mu}^{t_{1}}(a+b \mu) \mathrm{e}^{\alpha s^{\beta}} \mathrm{d} s\right]$, and the time-dependent on-hand inventory level in period $\left[\mu, t_{1}\right]$ to be $\mathrm{e}^{-\alpha t^{\beta}} \int_{t}^{t_{1}}(a+b \mu) \mathrm{e}^{\alpha s^{\beta}} \mathrm{d} s$. Therefore, by presuming $C_{1}$ to be unit HC, the total HC per cycle $[0, T]$ is as follows

$$
\mathrm{HC}=C_{1}\left\{\int_{0}^{\mu} \mathrm{e}^{-\alpha t^{\beta}}\left(\int_{t}^{\mu}(a+b s) \mathrm{e}^{\alpha s^{\beta}} \mathrm{d} s+\int_{\mu}^{t_{1}}(a+b \mu) \mathrm{e}^{\alpha s^{\beta}} \mathrm{d} s\right) \mathrm{d} t+\int_{\mu}^{t_{1}} \mathrm{e}^{-\alpha t^{\beta}}\left(\int_{t}^{t_{1}}(a+b \mu) \mathrm{e}^{\alpha s^{\beta}} \mathrm{d} s\right) \mathrm{d} t\right\} .
$$

Again, analogous to equation (3.8), by presuming $C_{2}$ to be unit SC, the total SC per cycle $[0, T]$ is as follows

$$
\mathrm{SC}=C_{2}(a+b \mu) \int_{t_{1}}^{T} \frac{(T-t)}{1+\delta(T-t)} \mathrm{d} t .
$$

Also, analogous to equation (3.9), by presuming $C_{3}$ to be unit DC, the total DC per cycle $[0, T]$ is as follows

$$
\mathrm{DC}=C_{3}\left\{\left(\int_{0}^{\mu}(a+b s) \mathrm{e}^{\alpha s^{\beta}} \mathrm{d} s+\int_{\mu}^{t_{1}}(a+b \mu) \mathrm{e}^{\alpha s^{\beta}} \mathrm{d} s\right)-\left((a+b \mu) t_{1}-\frac{b}{2} \mu^{2}\right)\right\} .
$$


Next, analogous to equation (3.10), by presuming $C_{4}$ to be unit LS, the total LS per cycle $[0, T]$ is as follows

$$
\mathrm{LS}=C_{4} \delta(a+b \mu) \int_{t_{1}}^{T} \frac{(T-t)}{1+\delta(T-t)} \mathrm{d} t .
$$

Next, this article deliberates across various sub-intervals based on fully permissible delay in payment as follows

\subsubsection{Trade-credit period lies within variable demand structure $(0 \leq \sigma \leq \mu)$}

In this sub-interval, the proposed model allows fully permissible delay in payment up to period $\sigma$. However, after the fixed settlement period $[0, \sigma]$, the retailer fully pays back the amount along with interest at a rate $I_{p}$. So, analogous to equation (3.11), the IP per cycle $[0, T]$ from equation (4.2) is as follows

$$
\operatorname{IP}_{1.1}=c I_{p}\left\{\int_{\sigma}^{\mu} \mathrm{e}^{-\alpha t^{\beta}}\left(\int_{t}^{\mu}(a+b s) \mathrm{e}^{\alpha s^{\beta}} \mathrm{d} s+\int_{\mu}^{t_{1}}(a+b \mu) \mathrm{e}^{\alpha s^{\beta}} \mathrm{d} s\right) \mathrm{d} t+\int_{\mu}^{t_{1}} \mathrm{e}^{-\alpha t^{\beta}}\left(\int_{t}^{t_{1}}(a+b \mu) \mathrm{e}^{\alpha s^{\beta}} \mathrm{d} s\right) \mathrm{d} t\right\}
$$

And, analogous to equation (3.12), the IE per cycle $[0, T]$ is as follows

$$
\mathrm{IE}_{1.1}=p I_{e} \int_{0}^{\sigma} t(a+b t) \mathrm{d} t
$$

Hence, the TAC per cycle $[0, T]$ is as follows

$$
\begin{aligned}
\operatorname{TAC}\left(t_{1}\right)= & \frac{1}{T}\left[A+C_{1}\left\{\int_{0}^{\mu} \mathrm{e}^{-\alpha t^{\beta}}\left(\int_{t}^{\mu}(a+b s) \mathrm{e}^{\alpha s^{\beta}} \mathrm{d} s+\int_{\mu}^{t_{1}}(a+b \mu) \mathrm{e}^{\alpha s^{\beta}} \mathrm{d} s\right) \mathrm{d} t\right.\right. \\
& \left.+\int_{\mu}^{t_{1}} \mathrm{e}^{-\alpha t^{\beta}}\left(\int_{t}^{t_{1}}(a+b \mu) \mathrm{e}^{\alpha s^{\beta}} \mathrm{d} s\right) \mathrm{d} t\right\}+\left(C_{2}+C_{4} \delta\right)(a+b \mu) \int_{t_{1}}^{T} \frac{T-t}{1+\delta(T-t)} \mathrm{d} t \\
& +C_{3}\left\{\int_{0}^{\mu}(a+b t) \mathrm{e}^{\alpha t^{\beta}} \mathrm{d} t+\int_{\mu}^{t_{1}}(a+b \mu) \mathrm{e}^{\alpha t^{\beta}} \mathrm{d} t-(a+b \mu) t_{1}+\frac{b}{2} \mu^{2}\right\} \\
& +c I_{p}\left[\int_{\sigma}^{\mu} \mathrm{e}^{-\alpha t^{\beta}}\left\{\int_{t}^{\mu}(a+b s) \mathrm{e}^{\alpha s^{\beta}} \mathrm{d} s+\int_{\mu}^{t_{1}}(a+b \mu) \mathrm{e}^{\alpha s^{\beta}} \mathrm{d} s\right\} \mathrm{d} t\right. \\
& \left.\left.+\int_{\mu}^{t_{1}} \mathrm{e}^{-\alpha t^{\beta}}\left(\int_{t}^{t_{1}}(a+b \mu) \mathrm{e}^{\alpha s^{\beta}} \mathrm{d} s\right) \mathrm{d} t\right]-p I_{e} \int_{0}^{\sigma} t(a+b t) \mathrm{d} t\right] .
\end{aligned}
$$

Next, this article replicates all intermediate equations from (3.14) to (3.18) and then finds that the duly formulated expression of TAC is highly non-linear in $t_{1}$. Therefore, TAC is minimum, when the following equation in $t_{1}$ holds (see Appendix B)

$$
C_{1} \mathrm{e}^{\alpha t_{1}^{*^{\beta}}} \int_{0}^{t_{1}^{*}} \mathrm{e}^{-\alpha t^{\beta}} \mathrm{d} t+C_{3}\left(\mathrm{e}^{\alpha t_{1}^{*^{\beta}}}-1\right)-\frac{\left(C_{2}+C_{4} \delta\right)\left(T-t_{1}^{*}\right)}{1+\delta\left(T-t_{1}^{*}\right)}+c I_{p} \mathrm{e}^{\alpha t_{1}^{*^{\beta}}} \int_{\sigma}^{t_{1}^{*}} \mathrm{e}^{-\alpha t^{\beta}} \mathrm{d} t=0
$$

Here, Figure 2a echoes above inference graphically that the function TAC is convex in $0 \leq \sigma \leq \mu$. The equation (4.12) yields $t_{1}^{*}$ so as to get the minimum value of TAC.

4.1.2. Trade-credit period lies during constant demand structure $\left(\mu \leq \sigma \leq t_{1}\right)$

Analogous to equation (3.11), the IP per cycle $[0, T]$ from equation (4.2) as follows

$$
\mathrm{IP}_{1.2}=c I_{p} \int_{\sigma}^{t_{1}} \mathrm{e}^{-\alpha t^{\beta}}\left(\int_{t}^{t_{1}}(a+b \mu) \mathrm{e}^{\alpha s^{\beta}} \mathrm{d} s\right) \mathrm{d} t .
$$


And, analogous to equation (3.12), the IE per cycle $[0, T]$ is as follows

$$
\mathrm{IE}_{1.2}=p I_{e} \int_{0}^{\mu} t(a+b t) \mathrm{d} t+\int_{\mu}^{\sigma} t(a+b \mu) \mathrm{d} t .
$$

Hence, the TAC per cycle $[0, T]$ is as follows

$$
\begin{aligned}
\operatorname{TAC}\left(t_{1}\right)= & \frac{1}{T}\left[A+C_{1}\left\{\int_{0}^{\mu} \mathrm{e}^{-\alpha t^{\beta}}\left(\int_{t}^{\mu}(a+b s) \mathrm{e}^{\alpha s^{\beta}} \mathrm{d} s+\int_{\mu}^{t_{1}}(a+b \mu) \mathrm{e}^{\alpha s^{\beta}} \mathrm{d} s\right) \mathrm{d} t\right.\right. \\
& \left.+\int_{\mu}^{t_{1}} \mathrm{e}^{-\alpha t^{\beta}}\left(\int_{t}^{t_{1}}(a+b \mu) \mathrm{e}^{\alpha s^{\beta}} \mathrm{d} s\right) \mathrm{d} t\right\}+\left(C_{2}+C_{4} \delta\right)(a+b \mu) \int_{t_{1}}^{T} \frac{T-t}{1+\delta(T-t)} \mathrm{d} t \\
& +C_{3}\left\{\int_{0}^{\mu}(a+b t) \mathrm{e}^{\alpha t^{\beta}} \mathrm{d} t+\int_{\mu}^{t_{1}}(a+b \mu) \mathrm{e}^{\alpha t^{\beta}} \mathrm{d} t-(a+b \mu) t_{1}+\frac{b}{2} \mu^{2}\right\} \\
& +c I_{p}\left\{\int_{\sigma}^{t_{1}} \mathrm{e}^{-\alpha t^{\beta}}\left(\int_{t}^{t_{1}}(a+b \mu) \mathrm{e}^{\alpha s^{\beta}} \mathrm{d} s\right) \mathrm{d} t\right\}-p I_{e}\left\{\int_{0}^{\mu} t(a+b t) \mathrm{d} t+\int_{\mu}^{\sigma} t(a+b \mu) \mathrm{d} t\right\} .
\end{aligned}
$$

Next, analogous to Case 3.1, the intermediate equations are from (3.14) to (3.18). Here, the corresponding duly formulated expression of TAC is highly non-linear in $t_{1}$. Whenever the following equation in $t_{1}$ holds, the minimum value of TAC is as follows (see Appendix C)

$$
C_{1} \mathrm{e}^{\alpha t_{1}^{*^{\beta}}} \int_{0}^{t_{1}^{*}} \mathrm{e}^{-\alpha t^{\beta}} \mathrm{d} t+C_{3}\left(\mathrm{e}^{\alpha t_{1}^{* \beta}}-1\right)-\frac{\left(C_{2}+C_{4} \delta\right)\left(T-t_{1}^{*}\right)}{1+\delta\left(T-t_{1}^{*}\right)}+c I_{p} \mathrm{e}^{\alpha t_{1}^{*^{\beta}}} \int_{\sigma}^{t_{1}^{*}} \mathrm{e}^{-\alpha t^{\beta}} \mathrm{d} t=0
$$

Also, Figure 2c echoes above inference graphically that the function TAC is convex in $\mu \leq \sigma \leq t_{1}$. Here, the equation (4.16) yields $t_{1}^{*}$ so as to obtain minimum value of TAC.

\subsubsection{Trade-credit period lies after total inventory depletion time $\left(t_{1} \leq \sigma \leq T\right)$}

Analogous to Case 3.2, retailer has accumulated the fund in various ways. So, total interest payable in $[0, T]$ is nil, i.e. $\mathrm{IP}_{2}=0$, and total interest earned in per cycle $[0, T]$ is as follows

$$
\begin{aligned}
\mathrm{IE}_{2} & =p I_{e}\left[\int_{0}^{\mu} t(a+b t) \mathrm{d} t+\int_{\mu}^{t_{1}} t(a+b \mu) \mathrm{d} t+\left(\sigma-t_{1}\right)\left\{\int_{0}^{\mu}(a+b t) \mathrm{d} t+\int_{\mu}^{t_{1}}(a+b \mu) \mathrm{d} t\right\}\right] \\
& =p I_{e}\left\{(a+b \mu)\left(\sigma t_{1}-\frac{t_{1}^{2}}{2}\right)+\frac{b \mu^{2}}{2}\left(t_{1}-\sigma-\frac{\mu}{3}\right)\right\} .
\end{aligned}
$$

So, the TAC per cycle $[0, T]$ is as follows

$$
\begin{aligned}
\operatorname{TAC}\left(t_{1}\right)= & \frac{1}{T}\left[A+C_{1}\left\{\int_{0}^{\mu} \mathrm{e}^{-\alpha t^{\beta}}\left(\int_{t}^{\mu}(a+b t) \mathrm{e}^{\alpha t^{\beta}} \mathrm{d} t+\int_{\mu}^{t_{1}}(a+b \mu) \mathrm{e}^{\alpha t^{\beta}} \mathrm{d} t\right) \mathrm{d} t\right.\right. \\
& \left.+\int_{\mu}^{t_{1}} \mathrm{e}^{-\alpha t^{\beta}}\left(\int_{t}^{t_{1}}(a+b \mu) \mathrm{e}^{\alpha t^{\beta}} \mathrm{d} t\right) \mathrm{d} t\right\}+\left(C_{2}+C_{4} \delta\right)(a+b \mu) \int_{t_{1}}^{T} \frac{T-t}{1+\delta(T-t)} \mathrm{d} t \\
& +C_{3}\left\{\int_{0}^{\mu}(a+b t) \mathrm{e}^{\alpha t^{\beta}} \mathrm{d} t+\int_{\mu}^{t_{1}}(a+b \mu) \mathrm{e}^{\alpha t^{\beta}} \mathrm{d} t-(a+b \mu) t_{1}+\frac{b}{2} \mu^{2}\right\} \\
& \left.-p I_{e}\left\{(a+b \mu)\left(\sigma t_{1}-\frac{t_{1}^{2}}{2}\right)+\frac{b \mu^{2}}{2}\left(t_{1}-\sigma-\frac{\mu}{3}\right)\right\}\right]
\end{aligned}
$$




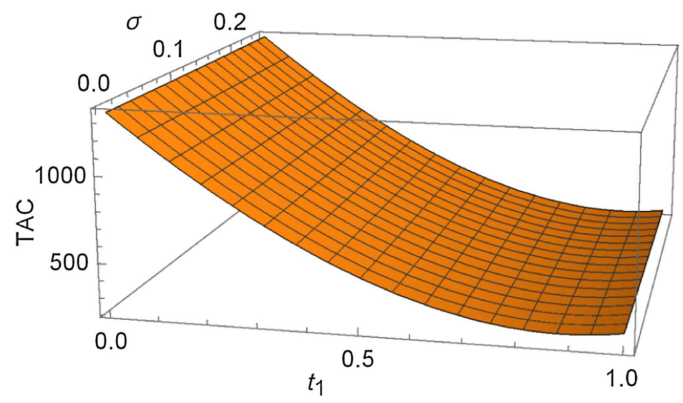

(a)

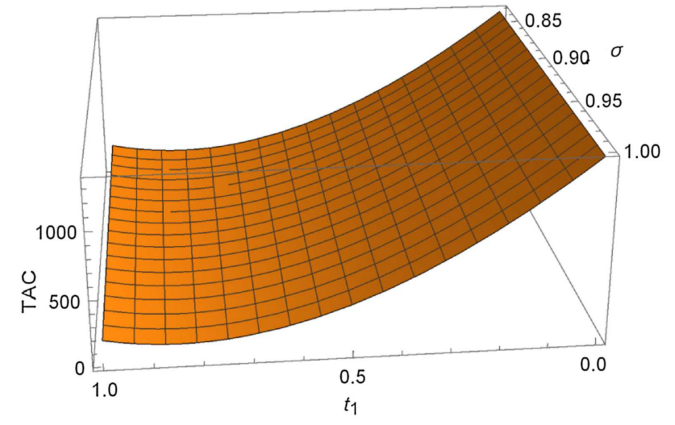

(b)

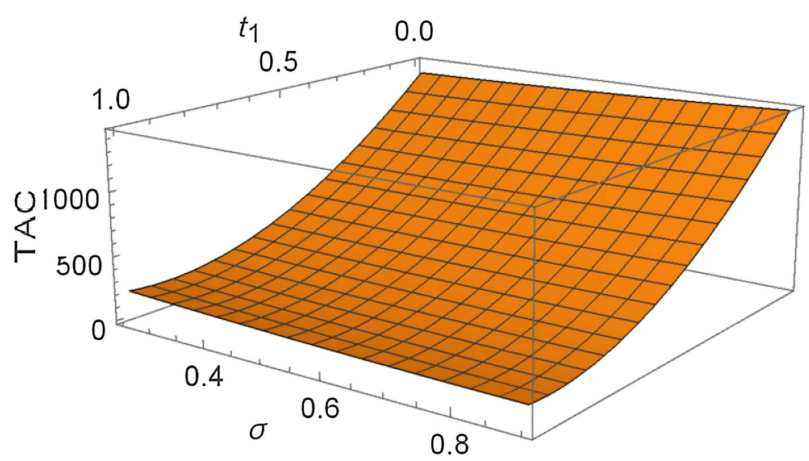

(c)

FIgURE 2. Graphical illustrations of TAC versus $t_{1}$ and $\sigma$ in various trade-credit periods. (a) TAC versus $t_{1}$ and $\sigma$ in trade-credit period $0 \leq \sigma \leq \mu$. (b) TAC versus $t_{1}$ and $\sigma$ in trade-credit period $t_{1} \leq \sigma \leq T$. (c) TAC versus $t_{1}$ and $\sigma$ in trade-credit period $\mu \leq \sigma \leq t_{1}$.

Analogous to previous case, the highly non-linear equation in inventory depletion time $t_{1}$, which in turn offers the minimum value of TAC is as follows (see Appendix D)

$$
(a+b \mu)\left\{C_{1} \mathrm{e}^{\alpha t_{1}^{* \beta}} \int_{0}^{t_{1}^{*}} \mathrm{e}^{-\alpha t^{\beta}} \mathrm{d} t+C_{3}\left(\mathrm{e}^{\alpha t_{1}^{* \beta}}-1\right)-\frac{\left(C_{2}+C_{4} \delta\right)\left(T-t_{1}^{*}\right)}{1+\delta\left(T-t_{1}^{*}\right)}-p I_{e}\left(\sigma-t_{1}^{*}\right)\right\}-p I_{e} \frac{b}{2} \mu^{2}=0 .
$$

Above equation (4.19) yields optimal inventory depletion time $t_{1}^{*}$ that minimizes value of TAC. Moreover, Figure $2 \mathrm{~b}$ echoes above inference graphically that the function TAC is convex in $t_{1} \leq \sigma \leq T$.

\subsection{Some special cases}

The proposed generalized order-level inventory system with fully permissible delay in payment turns to several existing and well-established EOQ models under various specific considerations as follows

- In case of quadratic demand, i.e. $D(t)=a+b t+c t^{2}, a>0, b \neq 0, c \neq 0$; time-dependent Weibull distribution deterioration, i.e. $\theta(t)=\alpha \beta t^{\beta-1}, 0<\alpha<1$, and $\beta>0$; fully backordering shortages i.e. $\lambda(T-t)=1$; no permissible delay in payment, i.e. $\sigma=0$ and no trade-credit policy, i.e. $I_{p}=0, I_{e}=0$; the proposed model reduces to model of Kavitha Priya and Senbagam [25].

- In case of selling price dependent time-dependent demand, i.e. $D(t)=\lambda_{0} \mathrm{e}^{-\lambda_{1} t}+\mu_{0} \mathrm{e}^{-\mu_{1}\left(s_{0}-s_{1} t\right)}$; deterioration is not allowed, i.e. $\theta(t)=0$; shortages are partially backordered of constant fraction $(1-k)$, i.e. $\lambda(T-t)=$ 
$(1-k), 0 \leq k \leq 1$; no permissible delay in payment, i.e. $\sigma=0$ and no trade-credit policy, i.e. $I_{p}=0, I_{e}=0$; the proposed model reduces to model of Mukhopadhyay and Goswami [37].

- In case of quadratic demand, i.e. $D(t)=a+b t+c t^{2}, a>0, b \neq 0, c \neq 0$; time-dependent deterioration, i.e. $\theta(t)=\theta(t)$; no shortages is allowed i.e. $\lambda(T-t)=0$; the proposed model reduces to model of Singh and Pattanayak [61].

- In case of quadratic demand, i.e. $D(t)=a+b t+c t^{2}, a>0, b \neq 0, c \neq 0$; constant deterioration, i.e. $\theta(t)=\theta$; no shortages is allowed i.e. $\lambda(T-t)=0$; the proposed model reduces to model of Khanra et al. [26].

- In case of no permissible delay in payment, i.e. $\sigma=0$ and no trade-credit policy, i.e. $I_{p}=0, I_{e}=0$; the proposed model reduces to model of Hung [21].

- In case of generalized time-dependent ramp type demand rate, i.e. $D(t)=\left\{\begin{array}{ll}f(t) & \text { if } t<\mu \\ f(\mu) & \text { if } t \geq \mu .\end{array}\right.$; Weibull distribution rate of deterioration, i.e. $\theta(t)=a b t^{b-1}$; no permissible delay in payment, i.e. $\sigma=0$ and no trade-credit policy, i.e. $I_{p}=0, I_{e}=0$; the proposed model reduces to model of Skouri et al. [64].

- In case of modified time-dependent ramp type demand rate, i.e. $D(t)=A \mathrm{e}^{[t-(t-\mu) H(t-\mu)]}$; three variables time-dependent Weibull distribution rate of deterioration, i.e. $\theta(t)=\alpha \beta(t-\gamma)^{\beta-1}$; fully backordering, i.e. $\lambda(T-t)=1$; no permissible delay in payment, i.e. $\sigma=0$ and no trade-credit policy, i.e. $I_{p}=0, I_{e}=0$; the proposed model reduces to model of Giri et al. [18].

- In case of time-dependent ramp type demand rate, i.e. $D(t)=D_{0}[t-(t-\mu) H(t-\mu)], D_{0}>0$; time-dependent Weibull distribution rate of deterioration, i.e. $\theta(t)=\alpha \beta t^{\beta-1}, 0<\alpha<1, \beta>0$; partial backordering, i.e. $\lambda(T-t)=\frac{1}{1+\delta(T-t)} ;$ no permissible delay in payment, i.e. $\sigma=0$ and no trade-credit policy, i.e. $I_{p}=0, I_{e}=0 ;$ the proposed model reduces to model of $\mathrm{Wu}[70]$.

- In case of time-dependent ramp type demand rate, i.e. $D(t)=D_{0}[t-(t-\mu) H(t-\mu)], D_{0}>0$; time-dependent Weibull distribution rate of deterioration, i.e. $\theta(t)=\alpha \beta t^{\beta-1}, 0<\alpha<1, \beta>0$; fully backordering, i.e. $\lambda(T-t)=1$; no permissible delay in payment, i.e. $\sigma=0$ and no trade-credit policy, i.e. $I_{p}=0, I_{e}=0$; the proposed model reduces to model of $\mathrm{Wu}$ [73].

- In case of time-dependent ramp type demand rate, i.e. $D(t)=D_{0}[t-(t-\mu) H(t-\mu)], D_{0}>0$; constant deterioration rate, i.e. $\theta(t)=\theta$; fully backordering, i.e. $\lambda(T-t)=1$; no permissible delay in payment, i.e. $\sigma=0$ and no trade-credit policy, i.e. $I_{p}=0, I_{e}=0$; the proposed model reduces to model of Mandal and Pal [32].

- In case of constant demand, i.e. $D(t)=D$; deterioration is not allowed, i.e. $\theta(t)=0$; shortage is not allowed i.e. $\lambda(T-t)=0$; no permissible delay in payment, i.e. $\sigma=0$ and no trade-credit policy, i.e. $I_{p}=0, I_{e}=0$; the proposed model reduces to traditional EOQ model.

\section{General algorithm}

The highly non-linear structure of relations, like (4.12), (4.16) and (4.19) fails to explicitly return the optimal inventory depletion time $\left(t_{1}^{*}\right)$, especially in numerical studies. However, software like MATLAB, MATHEMATICA etc. can numerically determine the value of $t_{1}^{*}, S^{*}, Q^{*}$ and subsequently TAC $\mathrm{T}^{*}$ through computer programming. Hence, this section presents one general algorithm that is a modification of the algorithm presented by Goyal [19]. Various steps of proposed algorithm that numerically optimizes the proposed generalized order-level inventory system with fully permissible delay in payment, are as follows

Step 1: Input all the parameters within the proposed model. Here, three sub-cases can arise as follows

$$
\text { if } \sigma<\mu \text {, go to Step 2; elseif } \sigma>\mu \text {, go to Step 3; elseif } \sigma=\mu \text {, go to Step } 4 \text {. }
$$

Step 2: Determine $t_{1}^{*}$ from equation (4.12).

If $\sigma<t_{1}^{*}$, find the optimal $\mathrm{TAC}^{*}$ from equation (4.11); elseif, $\sigma>t_{1}^{*}$, firstly, determine $t_{1}^{*}$ from equation (4.19) and thereby obtain the optimal TAC from equation (4.18); 
TABLE 2. Values of different parameters to be used in proposed model.

\begin{tabular}{llll}
\hline \hline Parameters & Values & Parameters & Values \\
\hline$C_{1}$ & $\$ 0.9 \backslash$ unit item $\backslash$ year & $\mu$ & $0.25 \backslash$ year \\
$C_{2}$ & $\$ 4 \backslash$ unit item $\backslash$ year & $c$ & $\$ 6 \backslash$ unit item \\
$C_{3}$ & $\$ 8 \backslash$ unit item & $p$ & $\$ 10 \backslash$ unit item \\
$C_{4}$ & $\$ 5 \backslash$ unit item & $T$ & 1 year \\
$a$ & $500 \backslash$ unit item $\backslash$ year & $\alpha$ & 0.06 \\
$b$ & $0.05 \backslash$ unit item $\backslash$ year & $\beta$ & 2 \\
\hline
\end{tabular}

elseif, $\sigma=t_{1}^{*}$, firstly determine $t_{1}^{*}$ from equation (4.12) and find corresponding TAC ${ }^{*}$ from equation (4.11), and then determine $t_{1}^{*}$ from equation (4.19) and find corresponding TAC $^{*}$ from equation (4.18). Finally, the optimal value of TAC is defined as the minimum value between those two values of $\mathrm{TAC}^{*}$.

Go to Step 5.

Step 3: Determine $t_{1}^{*}$ from equation (4.16).

If $\sigma<t_{1}^{*}$, find optimal $\mathrm{TAC}^{*}$ from equation (4.15);

elseif, $\sigma>t_{1}^{*}$, firstly, determine $t_{1}^{*}$ from equation (4.19) and thereby obtain the optimal TAC* from equation (4.18);

elseif, $\sigma=t_{1}^{*}$, firstly determine $t_{1}^{*}$ from equation (4.16) and find corresponding TAC* from equation (4.15), and then determine $t_{1}^{*}$ from equation (4.19) and find corresponding TAC ${ }^{*}$ from equation (4.18). Finally, the optimal value of TAC is defined as the minimum value between those two values of TAC $^{*}$.

Go to Step 5.

Step 4: Determine $t_{1}^{*}$ from equation (4.12) and find corresponding $\mathrm{TAC}^{*}$ from equation (4.11). Also, determine $t_{1}^{*}$ from equation (4.16) and find corresponding $\mathrm{TAC}^{*}$ from equation (4.15). Finally, the optimal value of TAC is defined as the minimum value between those two values of TAC*.

Go to Step 5.

Step 5: Compute initial inventory $\left(S^{*}\right)$ and optimal order quantity $\left(Q^{*}\right)$ at $t_{1}^{*}$.

The algorithm is thus complete.

\section{Numerical APplications}

The inspiration behind the data for numerical illustration to proposed EOQ model is primarily from the article of Chakraborty et al. [4]. Here, the input parameters from [4] are in Table 2.

In addition, the proposed inventory model considers the characteristics, like $I_{e}: 0.08 \%$ per year, $I_{p}: 0.10 \%$ per year [56].

Also, the value of replacement cost $(A)$ is $\$ 100$ per unit item and backordering parameter $(\delta)$ is 0.56 [70].

Since various scenarios can arise based on different sets of values of $\sigma$, this article considers each of those and follows the steps of general algorithm as presented in Section 5. All these Scenarios along with corresponding optimal values of TAC, $S$ and $Q$ are in Table 3 .

Below, optimal solutions under various scenarios to proposed EOQ model are compared with the articles from which numerical data are taken. The optimal values to proposed EOQ model are sometimes closer to the results of [4]. These authors observe that in each scenario to proposed model, the optimal values to $Q$ are much desirable than that of [4]. Moreover, when the optimal inventory depletion time is higher than 0.8 , the optimal values to TAC to present article are more and more preferable than that of [4]. The consideration of rate of inflation and fuzzy environment seems to illustrate more desirable optimal TAC in several cases to [4]. 
TABLE 3. Optimal solutions to proposed model in various trade-credit periods.

\begin{tabular}{|c|c|c|c|c|c|c|c|c|}
\hline Sl. No. & & Scenarios & $\sigma($ Year $)$ & $t_{1}^{*}($ Year $)$ & Interim TAC $(\$)$ & $\mathrm{TAC}^{*}(\$)$ & $S^{*}($ Unit item) & $Q^{*}$ (Unit item) \\
\hline \multirow{3}{*}{1.} & \multirow{3}{*}{$\sigma<\mu$} & $1.1 \sigma<t_{1}^{*}$ & 0.20 & 0.77 & 396.04 & 396.04 & 392.11 & 498.16 \\
\hline & & $1.2 \sigma>t_{1}^{*}$ & 0.96 & 0.84 & 168.67 & 168.67 & 424.19 & 502.41 \\
\hline & & $1.3 \sigma=t_{1}^{*}$ & 0.25 & $\begin{array}{l}0.82 \\
0.82\end{array}$ & $\begin{array}{l}214.08 \\
214.08\end{array}$ & 214.08 & 417.26 & 501.55 \\
\hline \multirow{3}{*}{2.} & \multirow{3}{*}{$\sigma>\mu$} & $2.1 \sigma<t_{1}^{*}$ & 0.40 & 0.79 & 342.68 & 342.68 & 400.36 & 499.32 \\
\hline & & $2.2 \sigma>t_{1}^{*}$ & 0.96 & 0.84 & 168.67 & 168.67 & 424.19 & 502.41 \\
\hline & & $2.3 \sigma=t_{1}^{*}$ & 0.82 & $\begin{array}{l}0.82 \\
0.82\end{array}$ & $\begin{array}{l}214.08 \\
214.08\end{array}$ & 214.08 & 417.26 & 501.55 \\
\hline 3. & $\sigma=\mu$ & $3.1 \sigma<t_{1}^{*}$ & $\begin{array}{l}0.20 \\
0.40\end{array}$ & $\begin{array}{l}0.78 \\
0.78\end{array}$ & $\begin{array}{l}391.57 \\
383.15 \\
\end{array}$ & 383.15 & 394.18 & 498.45 \\
\hline
\end{tabular}

As well, these authors wish to employ various imprecise environments to solve the proposed EOQ model in future studies.

Again, both, present article and [56] find the deterioration and holding cost to negatively influence the optimal TAC. The variations of optimal solutions in these two articles are due to different input values to parameters. This is to note that the much different values to input parameters in [70] than that of present study prevent the comparison between these two articles.

\section{SEnSitivity ANALYSis}

\subsection{Vulnerability of key parameters}

Modifications of system parameters within present study can alter the value of $t_{1}^{*}$ and thereby can change the optimal on-hand inventory level $\left(S^{*}\right)$, optimal order quantity $\left(Q^{*}\right)$ and optimal TAC $\left(\mathrm{TAC}^{*}\right)$. So, these authors perform the sensitivity analysis of parameters by changing values of parameters by $-50 \%,-20 \%, 20 \%$ and $50 \%$, by taking one parameter at a time and keeping the remaining parameters at original levels. This sensitivity analysis is based on the major Scenarios, such as (1.1), (2.1) and (2.2), in succession.

\subsubsection{Corresponding to particular Case 4.1.1}

The Scenario 1.1 numerically illustrates the particular Sub-case 4.1.1. Corresponding to this sub-case, the vulnerabilities of various parameters are in Table 4 . Here, TAC* is highly sensitive respect to changes in values of $C_{1}$ and $a$. This is moderately sensitive respect to changes in values of $C_{2}, C_{3}, C_{4}, \alpha, \beta, \sigma$ and $I_{p}$. Besides, value of $\mathrm{TAC}^{*}$ is slightly sensitive respect to changes in parameters, such as $\delta, \mu, b$ and $I_{e}$.

Again, whereas both $t_{1}^{*}$ and $S^{*}$ are moderately sensitive respect to changes in values of $C_{1}, C_{2}, C_{4}, \delta$ and $I_{p}$, both are slightly sensitive respect to changes in $C_{3}, \alpha, \beta$ and $\sigma$. However, the parameters, like $\mu, a, b$ and $I_{e}$ make hardly any impact on value of $t_{1}^{*}$ and those parameters, except $a$, slightly control value of $S^{*}$. Analogously, all these parameters slightly influence the value of $Q^{*}$, with the exception of $a$, one highly sensitive parameter for $S^{*}$. Besides, Figures 3-6. graphically illustrate above findings.

\subsubsection{Corresponding to particular Case 4.1.2}

The results in Table 5 corresponds to Scenario 2.1, which is a study of particular Sub-case 4.1.2. These results yield that values of $\mathrm{TAC}^{*}$ are highly sensitive respect to changes in values of parameters like $C_{1}, a$ and $\sigma$ and they are moderately sensitive respect to changes in values of parameters like $C_{2}, C_{3}, C_{4} \alpha, \beta, \delta$ and $I_{e}$. In addition, values of TAC* are slightly sensitive respect to changes in values of parameters $\mu, b$ and $I_{p}$.

On the other hand, whereas both $t_{1}^{*}$ and $S^{*}$ are moderately sensitive respect to changes in values of parameters like $C_{1}, C_{2}$ and $C_{4}$. However, values of $t_{1}^{*}$ are lowly sensitive and values of $S^{*}$ are moderately sensitive respect 
TABLE 4. Sensitivity analysis of parameters to proposed model in trade-credit period $[0, \mu]$.

\begin{tabular}{|c|c|c|c|c|c|}
\hline Parameter & $\%$ change & $\%$ change of $t_{1}^{*}$ & $\%$ change of $S^{*}$ & $\%$ change of $Q^{*}$ & $\%$ change of TAC ${ }^{*}$ \\
\hline \multirow{4}{*}{$C_{1}$} & 50 & -5.71 & -5.84 & -0.69 & 16.27 \\
\hline & 20 & -2.34 & -2.40 & -0.28 & 6.74 \\
\hline & -20 & 2.43 & 2.49 & 0.27 & -7.07 \\
\hline & -50 & 6.22 & 6.38 & 0.68 & -18.36 \\
\hline \multirow{4}{*}{$C_{2}$} & 50 & 5.44 & 5.58 & 0.60 & 4.84 \\
\hline & 20 & 2.45 & 2.51 & 0.28 & 2.17 \\
\hline & -20 & -2.94 & -3.01 & -0.35 & -2.59 \\
\hline & -50 & -8.62 & -8.80 & -1.07 & -7.58 \\
\hline \multirow{4}{*}{$C_{3}$} & 50 & -2.35 & -2.41 & -0.28 & 4.58 \\
\hline & 20 & -0.96 & -0.99 & -0.11 & 1.87 \\
\hline & -20 & 0.99 & 1.02 & 0.11 & -1.93 \\
\hline & -50 & 2.56 & 2.62 & 0.29 & -4.93 \\
\hline \multirow{4}{*}{$C_{4}$} & 50 & 4.03 & 4.14 & 0.45 & 3.58 \\
\hline & 20 & 1.76 & 1.80 & 0.20 & 1.56 \\
\hline & -20 & -1.99 & -2.04 & -0.23 & -1.76 \\
\hline & -50 & -5.55 & -5.67 & -0.67 & -4.89 \\
\hline \multirow{4}{*}{$\alpha$} & 50 & -2.59 & -2.09 & 0.14 & 4.90 \\
\hline & 20 & -1.06 & -0.85 & 0.06 & 2.01 \\
\hline & -20 & 1.10 & 0.87 & -0.07 & -2.06 \\
\hline & -50 & 2.81 & 2.22 & -0.20 & -5.27 \\
\hline \multirow{4}{*}{$\beta$} & 50 & 1.14 & 0.65 & -0.27 & -4.19 \\
\hline & 20 & 0.49 & 0.26 & -0.14 & -2.01 \\
\hline & -20 & -0.55 & -0.23 & 0.19 & 2.71 \\
\hline & -50 & -1.50 & -0.41 & 0.70 & 8.15 \\
\hline \multirow{4}{*}{$\delta$} & 50 & 3.01 & 3.08 & -0.14 & 2.97 \\
\hline & 20 & 1.29 & 1.32 & -0.07 & 1.28 \\
\hline & -20 & -1.44 & -1.47 & 0.10 & -1.43 \\
\hline & -50 & -3.93 & -4.02 & 0.33 & -3.92 \\
\hline \multirow{4}{*}{$\sigma$} & 50 & 1.03 & 1.06 & 0.12 & -6.59 \\
\hline & 20 & 0.41 & 0.42 & 0.05 & -2.59 \\
\hline & -20 & -0.41 & -0.42 & -0.05 & 2.55 \\
\hline & -50 & -1.04 & -1.06 & -0.12 & 6.28 \\
\hline \multirow{4}{*}{$\mu$} & 50 & 0.00 & -0.23 & $12 \mathrm{E}-5$ & $11 \mathrm{E}-5$ \\
\hline & 20 & 0.00 & -0.12 & $47 \mathrm{E}-6$ & $48 \mathrm{E}-6$ \\
\hline & -20 & 0.00 & -0.04 & $-47 \mathrm{E}-6$ & $-48 \mathrm{E}-6$ \\
\hline & -50 & 0.00 & -0.01 & $-12 \mathrm{E}-5$ & $-11 \mathrm{E}-5$ \\
\hline \multirow{4}{*}{$a$} & 50 & 0.00 & 49.99 & 49.99 & 37.37 \\
\hline & 20 & 0.00 & 19.99 & 20.00 & 14.95 \\
\hline & -20 & 0.00 & -19.99 & -20.00 & -14.95 \\
\hline & -50 & 0.00 & -49.99 & -49.99 & -37.37 \\
\hline \multirow{4}{*}{$b$} & 50 & 0.00 & $45 \mathrm{E}-5$ & $41 \mathrm{E}-5$ & $47 \mathrm{E}-5$ \\
\hline & 20 & 0.00 & $15 \mathrm{E}-5$ & $11 E-5$ & $12 \mathrm{E}-5$ \\
\hline & -20 & 0.00 & $-11 \mathrm{E}-5$ & $-12 \mathrm{E}-5$ & $-10 \mathrm{E}-5$ \\
\hline & -50 & 0.00 & $-41 \mathrm{E}-5$ & $-45 \mathrm{E}-5$ & $-47 \mathrm{E}-5$ \\
\hline \multirow{4}{*}{$I_{e}$} & 50 & 0.00 & 0.00 & $64 E-4$ & -1.01 \\
\hline & 20 & 0.00 & 0.00 & $40 \mathrm{E}-5$ & -0.40 \\
\hline & -20 & 0.00 & 0.00 & $-42 \mathrm{E}-5$ & 0.41 \\
\hline & -50 & 0.00 & 0.00 & $-66 \mathrm{E}-4$ & 1.01 \\
\hline \multirow{4}{*}{$I_{p}$} & 50 & -2.85 & -5.84 & -0.34 & 6.08 \\
\hline & 20 & -1.16 & -2.40 & -0.14 & 2.49 \\
\hline & -20 & 1.19 & 2.49 & 0.14 & -2.57 \\
\hline & -50 & 3.03 & 6.38 & 0.34 & -6.59 \\
\hline
\end{tabular}


to changes in values of parameter $I_{p}$. Here, the changes in values of parameters like $C_{3}, \alpha, \beta, \delta$ and $\sigma$ make very low impact on values of $t_{1}^{*}$ and $S^{*}$. Moreover, values of parameters such as $\mu, a, b$ and $I_{e}$ make hardly any impact on values of $t_{1}^{*}$. Besides, values of parameters like $\mu$ and $b$ slightly control and values of $a$ particularly controls the values of $S^{*}$. Analogously, all these parameters, except the highly sensitive parameter $a$, slightly influence values of $Q^{*}$. Besides, Figures 3-6. graphically illustrate the findings.

\subsubsection{Corresponding to particular Case 4.1.3}

Corresponding to Scenario 2.2, the results are in Table 6. In this study of particular Sub-case 4.1.3, the values of TAC* are highly sensitive respect to changes in values of parameters $C_{1}, C_{3}, \alpha, \beta, I_{e}, a$ and $\sigma$ and these are moderately sensitive respect to changes in values of parameters $C_{2}, C_{4}$ and $\delta$. Nevertheless, values of $\mathrm{TAC}^{*}$ are slightly sensitive respect to changes in values of parameters $\mu$ and $b$. Again, whereas both of $t_{1}^{*}$ and $S^{*}$ are moderately sensitive respect to changes in values of parameters $C_{1}, C_{2}$ and $\sigma$, these are slightly sensitive respect to changes in parameters $C_{3}, C_{4}, \alpha, \beta, \delta, \mu, a, b$ and $I_{e}$. Similarly, all these parameters, except the highly sensitive parameter $a$, slightly influences value of $Q^{*}$. Hence, from the numerical findings this article concludes that when the credit period is greater than the inventory depletion time for settling account, the optimal inventory depletion time varies inversely over demand. Indeed, the converse is not true i.e. when the credit period is less than inventory depletion time the optimal inventory depletion time is independent of demand. Also, the permissible period of delay in settling account is inversely proportional to $I_{e}$ and $I_{p}$. Besides, Figures 3-6 illustrate these graphically.
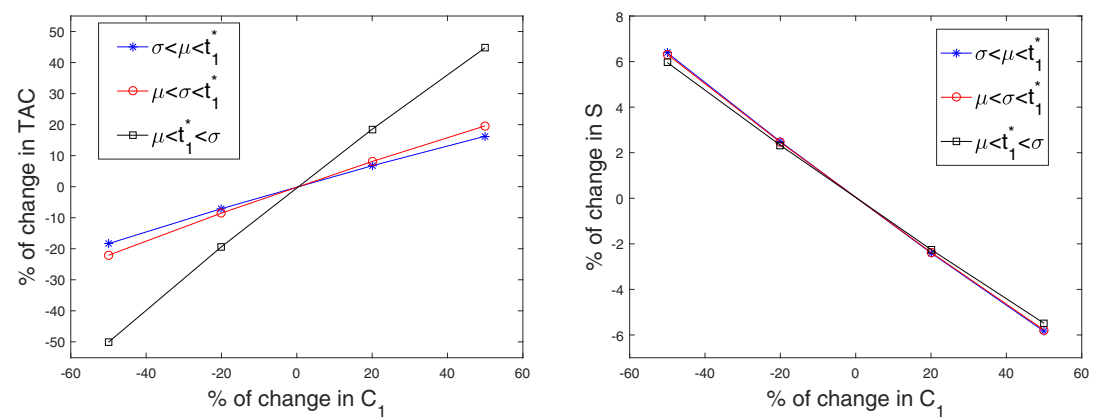

Figure 3 . Effect of changes of parameter $C_{1}$ on values of TAC* and $S^{*}$.
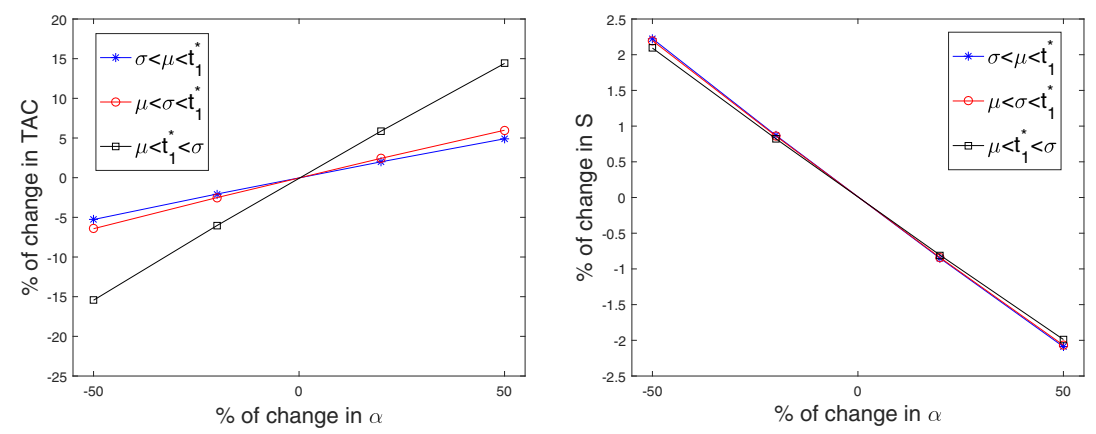

Figure 4 . Effect of changes of parameter $\alpha$ on values of TAC* and $S^{*}$. 

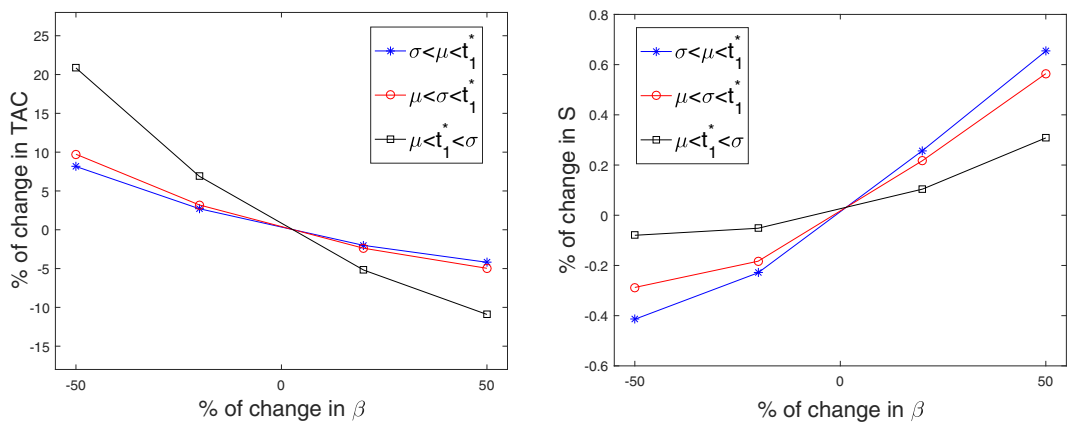

Figure 5. Effect of changes of parameter $\beta$ on values of TAC* and $S^{*}$.
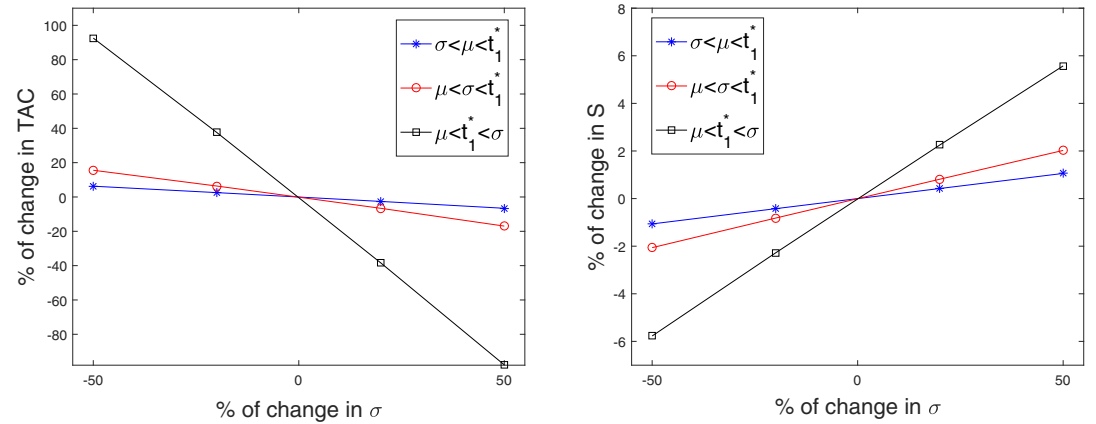

FiguRE 6. Effect of changes of parameter $\sigma$ on values of TAC* and $S^{*}$.

\subsection{Managerial insights}

The managerial insights extracted from above sensitivity analysis of parameters are as follows is sub-section leads to insights beyond the results of this investigation and focuses on managerial guidelines to assist the DM across industries as follows

Insight 1 . This analysis shows that the optimal inventory depletion time is independent of demand in timedependent on-hand inventory period. And, this optimal inventory depletion time decreases under higher demand in shortage period. However, the higher demand rapidly increases the optimal TAC at any time. So, in shortage period, the managers should plan to halt the promotional activities so as to foreshorten the demand.

Insight 2. The present analysis finds that whereas the higher HC increases the optimal TAC, this decreases the optimal initial inventory at any time. However, this can hardly influence the order quantity at any time. Analytic results of DC are analogous in nature. Therefore, when any of these costs increases, the managers should reduce the initial inventory. Besides, they should promote longer waiting period without reducing the next replenishment period.

In both cases, the resulting longer waiting period for fresh arrivals of retailers can be counterbalanced with promotional activities and anticipated benefits, like the updated design, slower deterioration, technologically advanced, environment-friendly raw materials and all that.

Insight 3. To proposed EOQ model, the longer the period of permissible delay in payment, the greater the improvement to optimal TAC. So, the retailers should accept a supplier's offer that has longer period of permissible delay. 
TABLE 5. Sensitivity analysis of parameters of proposed model in trade-credit period $\left[\mu, t_{1}\right]$.

\begin{tabular}{|c|c|c|c|c|c|}
\hline Parameter & $\%$ change & $\%$ change of $t_{1}^{*}$ & $\%$ change of $S^{*}$ & $\%$ change of $Q^{*}$ & $\%$ change of TAC* \\
\hline \multirow{4}{*}{$C_{1}$} & 50 & -5.65 & -5.78 & -0.67 & 19.60 \\
\hline & 20 & -2.32 & -2.38 & -0.27 & 8.12 \\
\hline & -20 & 2.40 & 2.46 & 0.27 & -8.52 \\
\hline & -50 & 6.14 & 6.31 & 0.65 & -22.09 \\
\hline \multirow{4}{*}{$C_{2}$} & 50 & 4.94 & 5.07 & 0.53 & 4.86 \\
\hline & 20 & 2.22 & 2.28 & 0.25 & 2.20 \\
\hline & -20 & -2.66 & -2.72 & -0.31 & -2.60 \\
\hline & -50 & -7.81 & -7.98 & -0.95 & -7.60 \\
\hline \multirow{4}{*}{$C_{3}$} & 50 & -2.37 & -2.43 & -0.27 & 5.63 \\
\hline & 20 & -0.97 & -0.99 & -0.11 & 2.30 \\
\hline & -20 & 1.01 & 1.03 & 0.11 & -2.37 \\
\hline & -50 & 2.58 & 2.65 & 0.29 & -6.07 \\
\hline \multirow{4}{*}{$C_{4}$} & 50 & 3.66 & 3.76 & 0.40 & 3.59 \\
\hline & 20 & 1.59 & 1.64 & 0.18 & 1.56 \\
\hline & -20 & -1.81 & -1.85 & -0.21 & -1.77 \\
\hline & -50 & -5.03 & -5.15 & -0.59 & -4.91 \\
\hline \multirow{4}{*}{$\alpha$} & 50 & -2.59 & -2.07 & 0.17 & 5.98 \\
\hline & 20 & -1.06 & -0.84 & 0.08 & 2.44 \\
\hline & -20 & 1.10 & 0.86 & -0.09 & -2.52 \\
\hline & -50 & 2.81 & 2.19 & -0.24 & -6.43 \\
\hline \multirow{4}{*}{$\beta$} & 50 & 1.06 & 0.56 & -0.29 & -4.97 \\
\hline & 20 & 0.45 & 0.22 & -0.15 & -2.38 \\
\hline & -20 & -0.50 & -0.18 & 0.21 & 3.20 \\
\hline & -50 & -1.37 & -0.29 & 0.74 & 9.73 \\
\hline \multirow{4}{*}{$\delta$} & 50 & 2.79 & 2.86 & -0.11 & 3.02 \\
\hline & 20 & 1.19 & 1.23 & -0.06 & 1.30 \\
\hline & -20 & -1.33 & -1.37 & 0.08 & -1.45 \\
\hline & -50 & -3.65 & -3.74 & 0.27 & -3.99 \\
\hline \multirow{4}{*}{$\sigma$} & 50 & 1.97 & 2.02 & 0.22 & -16.96 \\
\hline & 20 & 0.79 & 0.81 & 0.09 & -6.62 \\
\hline & -20 & -0.80 & -0.82 & -0.09 & 6.40 \\
\hline & -50 & -2.01 & -2.06 & -0.23 & 15.57 \\
\hline \multirow{4}{*}{$\mu$} & 50 & 0.00 & -0.23 & $11 \mathrm{E}-4$ & $71 \mathrm{E}-4$ \\
\hline & 20 & 0.00 & -0.12 & $47 \mathrm{E}-5$ & $36 \mathrm{E}-5$ \\
\hline & -20 & 0.00 & -0.04 & $-47 \mathrm{E}-5$ & $-34 \mathrm{E}-5$ \\
\hline & -50 & 0.00 & -0.01 & $-10 \mathrm{E}-4$ & $-71 \mathrm{E}-4$ \\
\hline \multirow{4}{*}{$a$} & 50 & 0.00 & 49.99 & 49.99 & 35.41 \\
\hline & 20 & 0.00 & 19.99 & 20.00 & 14.16 \\
\hline & -20 & 0.00 & -19.99 & -19.99 & -14.16 \\
\hline & -50 & 0.00 & -49.99 & -49.99 & -35.41 \\
\hline \multirow{4}{*}{$b$} & 50 & 0.00 & $11 \mathrm{E}-2$ & $11 \mathrm{E}-4$ & $10 \mathrm{E}-4$ \\
\hline & 20 & 0.00 & $47 \mathrm{E}-5$ & $47 \mathrm{E}-5$ & $47 \mathrm{E}-5$ \\
\hline & -20 & 0.00 & $-47 \mathrm{E}-5$ & $-47 \mathrm{E}-5$ & $-47 \mathrm{E}-5$ \\
\hline & -50 & 0.00 & $-11 \mathrm{E}-4$ & $-11 \mathrm{E}-4$ & $-10 \mathrm{E}-4$ \\
\hline \multirow{4}{*}{$I_{e}$} & 50 & 0.00 & 0.00 & $65 \mathrm{E}-4$ & -4.67 \\
\hline & 20 & 0.00 & 0.00 & $47 \mathrm{E}-5$ & -1.87 \\
\hline & -20 & 0.00 & 0.00 & $-47 \mathrm{E}-5$ & 1.87 \\
\hline & -50 & 0.00 & 0.00 & $-67 \mathrm{E}-4$ & 4.67 \\
\hline \multirow{4}{*}{$I_{p}$} & 50 & -1.86 & -5.78 & -0.21 & 3.25 \\
\hline & 20 & -0.76 & -2.38 & -0.09 & 1.33 \\
\hline & -20 & 0.77 & 2.46 & 0.09 & -1.37 \\
\hline & -50 & 1.99 & 6.31 & 0.22 & -3.51 \\
\hline
\end{tabular}


TABLE 6 . Sensitivity analysis of parameters of proposed model in trade-credit period $\left[t_{1}, T\right]$.

\begin{tabular}{|c|c|c|c|c|c|}
\hline Parameter & $\%$ change & $\%$ change of $t_{1}^{*}$ & $\%$ change of $S^{*}$ & $\%$ change of $Q^{*}$ & $\%$ change of TAC $^{*}$ \\
\hline \multirow{4}{*}{$C_{1}$} & 50 & -5.35 & -5.49 & -0.60 & 44.78 \\
\hline & 20 & -2.19 & -2.25 & -0.24 & 18.51 \\
\hline & -20 & 2.26 & 2.33 & 0.23 & -19.37 \\
\hline & -50 & 5.78 & 5.96 & 0.57 & -50.13 \\
\hline \multirow{4}{*}{$C_{2}$} & 50 & 3.53 & 3.64 & 0.36 & 6.15 \\
\hline & 20 & 1.58 & 1.63 & 0.16 & 2.75 \\
\hline & -20 & -1.88 & -1.94 & -0.20 & -3.2679 \\
\hline & -50 & -5.49 & -5.63 & -0.62 & -9.50 \\
\hline \multirow{4}{*}{$C_{3}$} & 50 & -2.37 & -2.43 & -0.26 & 13.56 \\
\hline & 20 & -0.97 & -0.99 & -0.11 & 5.54 \\
\hline & -20 & 1.00 & 1.03 & 0.10 & -5.71 \\
\hline & -50 & 2.57 & 2.65 & 0.26 & -14.60 \\
\hline \multirow{4}{*}{$C_{4}$} & 50 & 2.61 & 2.69 & 0.27 & 4.55 \\
\hline & 20 & 1.14 & 1.17 & 0.12 & 1.98 \\
\hline & -20 & -1.28 & -1.32 & -0.14 & -2.23 \\
\hline & -50 & -3.55 & -3.65 & -0.39 & -6.15 \\
\hline \multirow{4}{*}{$\alpha$} & 50 & -2.58 & -1.99 & 0.27 & 14.40 \\
\hline & 20 & -1.05 & -0.81 & 0.12 & 5.88 \\
\hline & -20 & 1.09 & 0.82 & -0.13 & -6.05 \\
\hline & -50 & 2.78 & 2.09 & -0.36 & -15.45 \\
\hline \multirow{4}{*}{$\beta$} & 50 & 0.81 & 0.31 & -0.36 & -10.91 \\
\hline & 20 & 0.35 & 0.10 & -0.18 & -5.19 \\
\hline & -20 & -0.38 & -0.05 & 0.24 & 6.89 \\
\hline & -50 & -1.00 & 0.08 & 0.83 & 20.85 \\
\hline \multirow{4}{*}{$\delta$} & 50 & 2.12 & 2.18 & -0.04 & 3.97 \\
\hline & 20 & 0.91 & 0.94 & -0.02 & 1.71 \\
\hline & -20 & -1.01 & -1.04 & 0.04 & -1.91 \\
\hline & -50 & -2.78 & -2.85 & 0.14 & -5.24 \\
\hline \multirow{4}{*}{$\sigma$} & 50 & 5.41 & 5.57 & 0.53 & -97.81 \\
\hline & 20 & 2.19 & 2.25 & 0.22 & -38.51 \\
\hline & -20 & -2.22 & -2.28 & -0.24 & 37.67 \\
\hline & -50 & -5.63 & -5.77 & -0.63 & 92.56 \\
\hline \multirow{4}{*}{$\mu$} & 50 & $44 \mathrm{E}-6$ & $85 \mathrm{E}-5$ & $97 \mathrm{E}-5$ & $60 \mathrm{E}-5$ \\
\hline & 20 & $15 \mathrm{E}-6$ & $49 \mathrm{E}-5$ & $49 \mathrm{E}-5$ & $27 \mathrm{E}-5$ \\
\hline & -20 & $-12 \mathrm{E}-6$ & $-42 \mathrm{E}-5$ & $-35 \mathrm{E}-5$ & $-35 \mathrm{E}-5$ \\
\hline & -50 & $-26 \mathrm{E}-6$ & $-17 \mathrm{E}-4$ & $-95 \mathrm{E}-5$ & $-67 \mathrm{E}-5$ \\
\hline \multirow{4}{*}{$a$} & 50 & $-11 \mathrm{E}-6$ & 49.99 & 49.99 & 20.36 \\
\hline & 20 & $-56 \mathrm{E}-7$ & 19.99 & 19.99 & 8.14 \\
\hline & -20 & $46 \mathrm{E}-7$ & -19.99 & -19.99 & -8.14 \\
\hline & -50 & $35 \mathrm{E}-6$ & -49.99 & -49.99 & -20.36 \\
\hline \multirow{4}{*}{$b$} & 50 & $17 \mathrm{E}-6$ & $11 \mathrm{E}-4$ & $12 \mathrm{E}-4$ & $54 \mathrm{E}-5$ \\
\hline & 20 & $71 \mathrm{E}-7$ & $49 \mathrm{E}-5$ & $51 \mathrm{E}-5$ & $29 \mathrm{E}-5$ \\
\hline & -20 & $-71 \mathrm{E}-7$ & $-68 \mathrm{E}-5$ & $-44 \mathrm{E}-5$ & $-20 \mathrm{E}-5$ \\
\hline & -50 & $-17 \mathrm{E}-6$ & $-11 \mathrm{E}-4$ & $-10 \mathrm{E}-4$ & $-54 \mathrm{E}-5$ \\
\hline \multirow{4}{*}{$I_{e}$} & 50 & 0.68 & 0.69 & 0.07 & -53.78 \\
\hline & 20 & 0.28 & 0.29 & 0.03 & -21.50 \\
\hline & -20 & -0.29 & -0.29 & -0.03 & 21.49 \\
\hline & -50 & -0.75 & -0.77 & -0.08 & 53.69 \\
\hline \multirow{4}{*}{$I_{p}$} & 50 & 0.00 & 0.00 & 0.00 & 0.00 \\
\hline & 20 & 0.00 & 0.00 & 0.00 & 0.00 \\
\hline & -20 & 0.00 & 0.00 & 0.00 & 0.00 \\
\hline & -50 & 0.00 & 0.00 & 0.00 & 0.00 \\
\hline
\end{tabular}


Insight 4. In time-dependent on-hand inventory period, the retailers have to pay interest on goods. So, they tend to order lesser quantity of goods. However, the proposed model contradicts that perception. This model recommends to reduce the initial inventory while keeping the order quantity at around same level in this period.

Insight 5. In shortage period, the retailers tend to order larger quantity of goods due to anticipated demand from retailers. However, this analysis suggests that the retailers should place the order for around same quantity of goods so as to rapidly decrease the optimal TAC.

Above insights present win-win situations to both suppliers and retailers to any EOQ model under timedependent ramp type demand rate, time-dependent Weibull distribution rate of deterioration and permissible delay in payment.

\subsection{Areas of application to proposed model}

The proposed model is potentially applicable to the average inventory managers, who order the items from suppliers and sell to customers in supermarkets (e.g., Wal-Mart and Carrefour). Also, this model is applicable to businesses that handle the perishable products (e.g., fruits, vegetables, pharmacies etc.); the electronic components (e.g., transistors, silicon-controlled rectifiers, capacitors etc.); the household items (e.g., air conditioners, refrigerators, mixer etc.) and all that.

\section{Conclusions}

This article presented a closed-form EOQ model with the general type demand rate, general type rate of deterioration, general type partial backorder along with fully permissible delay in payment across various tradecredit intervals. The review of existing and well-established articles found the optimal inventory depletion time to be independent of the demand over entire cycle. However, under the hypotheses presented in Section 3.2, this article studied two sub-cases that were based on the settlement time of account. The Case 3.2 in Section 3 found that when the trade-credit period was longer than or equal to the inventory depletion time to settle the account, optimal inventory depletion time varied over demand.

Under this ambiance, this article examined one particular case within proposed EOQ model. Here, Section 4 considered the time-dependent ramp type demand rate function, time-dependent Weibull distribution rate of deterioration and partial backorder under fully permissible delay in payment. Analogous to general Case 3.2, Case 4.1.3 in Section 4.1 found that when the trade-credit period had crossed the inventory depletion time to settle the account under the consideration of delay in payment; the optimal inventory depletion time varied inversely over demand. In addition, the proposed EOQ model shrank to various existing and well-established EOQ models under fully permissible delay in payment and some other specific considerations. Next, this article modified the algorithm of Goyal [61] in Section 5 in order to determine the optimal inventory depletion time $\left(t_{1}^{*}\right)$ and thereby optimal on-hand inventory level $\left(S^{*}\right)$, optimal order quantity $\left(Q^{*}\right)$ and optimal TAC $\left(\mathrm{TAC}^{*}\right)$. Numerically, the proposed EOQ model was solved corresponding to three major scenarios that were further divided into seven sub-cases.

The sensitivity analysis of key parameters in Section 7.1 yielded several managerial insights. This article suggested the managers to halt the promotional activities so as to foreshorten the demand during shortages. Moreover, this analysis found that the longer waiting period for fresh arrivals, which resulted into reduced TAC of retailers should be counterbalanced through the advertisements and anticipated benefits.

The numerous complexities within the EOQ models remain beyond the full capture of one single model, even after many years of in-depth researches. So, the scopes for future research based on present study are ample. This article considered the lead time to be zero in order to simplify the process. However, the lead time can be constant, discrete, negative exponential or stochastic in nature to real-life based EOQ models. Besides, the ordering cost can have linear and non-linear relationships with lead time in future studies. Future researchers can consider many other indices, like multi-item, retail inflation rate, perishability, quantity discount and all 
that in EOQ studies. And, last but not the least, one can extend the proposed model to different real-life based imprecise environments, like stochastic environment, fuzzy environment, soft environment, rough environment, neutrosophic environment and so on.

\section{Appendix A.}

Statement A.1. Deduce the optimality condition of TAC, where

$$
\begin{aligned}
\operatorname{TAC}\left(t_{1}\right)= & \frac{1}{T}\left[A+C_{1} \int_{0}^{t_{1}} \mathrm{e}^{-\int_{0}^{t} \theta(x) \mathrm{d} x}\left(\int_{t}^{t_{1}} D(s) \mathrm{e}^{\int_{0}^{s} \theta(x) \mathrm{d} x} \mathrm{~d} s\right) \mathrm{d} t+C_{3} \int_{0}^{t_{1}} D(s)\left(\mathrm{e}^{\int_{0}^{s} \theta(x) \mathrm{d} x}-1\right) \mathrm{d} s\right. \\
& +C_{2} \int_{t_{1}}^{T} \int_{t_{1}}^{t} D(s) \lambda(T-s) \mathrm{d} s \mathrm{~d} t+C_{4} \int_{t_{1}}^{T}[1-\lambda(T-t)] D(t) \mathrm{d} t-p I_{e}\left\{\int_{0}^{t_{1}} t D(t) \mathrm{d} t\right. \\
& \left.\left.+\left(\sigma-t_{1}\right) \int_{0}^{t_{1}} D(t) \mathrm{d} t\right\}\right]
\end{aligned}
$$

Proof. For the above expression of TAC, the first order differential quotient of $\mathrm{TAC}\left(t_{1}\right)$ with respect to $t_{1}$ is as follows

$$
\begin{aligned}
\frac{\mathrm{dTAC}\left(t_{1}\right)}{\mathrm{d} t_{1}}= & \frac{D\left(t_{1}\right)}{T}\left[C_{1} \mathrm{e}^{t_{0}^{t_{1}} \theta(x) \mathrm{d} x} \int_{0}^{t_{1}} \mathrm{e}^{-\int_{0}^{t} \theta(x) \mathrm{d} x} \mathrm{~d} t+C_{3}\left(\mathrm{e}^{\int_{0}^{t_{1}} \theta(x) \mathrm{d} x}-1\right)-\left\{\left(C_{2}\left(T-t_{1}\right)-C_{4}\right)\right.\right. \\
& \left.\left.\times \lambda\left(T-t_{1}\right)+C_{4}\right\}-p I_{e} \sigma\right]+\frac{p I_{e}}{T} \int_{0}^{t_{1}} D(t) \mathrm{d} t
\end{aligned}
$$

Here, the necessary condition of optimality for TAC, which is a function of single variable, yields the critical points from the equation (3.21). Now, the second order differential quotient of $\mathrm{TAC}\left(t_{1}\right)$ with respect to $t_{1}$ is as follows

$$
\begin{aligned}
\frac{\mathrm{d}^{2} \mathrm{TAC}\left(t_{1}\right)}{\mathrm{d} t_{1}^{2}}= & \frac{D^{\prime}\left(t_{1}\right)}{T}\left[C_{1} \mathrm{e}^{\int_{0}^{t_{1}} \theta(x) \mathrm{d} x} \int_{0}^{t_{1}} \mathrm{e}^{-\int_{0}^{t} \theta(x) \mathrm{d} x} \mathrm{~d} t+C_{3}\left(\mathrm{e}^{\int_{0}^{t_{1}} \theta(x) \mathrm{d} x}-1\right)-\left\{\left(C_{2}\left(T-t_{1}\right)-C_{4}\right) \lambda\left(T-t_{1}\right)\right.\right. \\
& \left.\left.+C_{4}\right\}-p I_{e} \sigma\right]+\frac{D\left(t_{1}\right)}{T}\left[C_{1}\left\{1+\theta\left(t_{1}\right) \mathrm{e}^{\int_{0}^{t_{1}} \theta(x) \mathrm{d} x} \int_{0}^{t_{1}} \mathrm{e}^{-\int_{0}^{t} \theta(x) \mathrm{d} x} \mathrm{~d} t\right\}+C_{3} \theta\left(t_{1}\right) \mathrm{e}^{t_{0}^{t_{1}} \theta(x) \mathrm{d} x}\right. \\
& \left.+C_{2}\left\{\lambda\left(T-t_{1}\right)+\left(T-t_{1}\right) \beta^{\prime}\left(T-t_{1}\right)\right\}+C_{4}\left(-\beta^{\prime}\left(T-t_{1}\right)\right)+p I_{e}\right]
\end{aligned}
$$

The sufficient condition for existence of minimum value of $\operatorname{TAC}\left(t_{1}\right), \frac{\mathrm{d}^{2} \mathrm{TAC}\left(t_{1}\right)}{\mathrm{d} t_{1}^{2}}$ is positive and satisfied whenever following relation holds at the critical point $t_{1}=t_{1}^{*}$

$$
C_{1} \mathrm{e}^{\int_{0}^{t_{1}^{*}} \theta(x) \mathrm{d} x} \int_{0}^{t_{1}^{*}} \mathrm{e}^{-\int_{0}^{t} \theta(x) \mathrm{d} x} \mathrm{~d} t+C_{3}\left(\mathrm{e}^{\int_{0}^{t_{1}^{*}} \theta(x) \mathrm{d} x}-1\right)>\left\{\left(C_{2}\left(T-t_{1}^{*}\right)-C_{4}\right) \lambda\left(T-t_{1}^{*}\right)+C_{4}\right\}+p I_{e} \sigma
$$

Hence the result. 


\section{Appendix B.}

Statement B.1. Deduce the optimality condition of TAC, where

$$
\begin{aligned}
\operatorname{TAC}\left(t_{1}\right)= & \frac{1}{T}\left[A+C_{1}\left\{\int_{0}^{\mu} \mathrm{e}^{-\alpha t^{\beta}}\left(\int_{t}^{\mu}(a+b s) \mathrm{e}^{\alpha s^{\beta}} \mathrm{d} s+\int_{\mu}^{t_{1}}(a+b \mu) \mathrm{e}^{\alpha s^{\beta}} \mathrm{d} s\right) \mathrm{d} t\right.\right. \\
& \left.+\int_{\mu}^{t_{1}} \mathrm{e}^{-\alpha t^{\beta}}\left(\int_{t}^{t_{1}}(a+b \mu) \mathrm{e}^{\alpha s^{\beta}} \mathrm{d} s\right) \mathrm{d} t\right\}+\left(C_{2}+C_{4} \delta\right)(a+b \mu) \int_{t_{1}}^{T} \frac{T-t}{1+\delta(T-t)} \mathrm{d} t \\
& +C_{3}\left\{\int_{0}^{\mu}(a+b t) \mathrm{e}^{\alpha t^{\beta}} \mathrm{d} t+\int_{\mu}^{t_{1}}(a+b \mu) \mathrm{e}^{\alpha t^{\beta}} \mathrm{d} t-(a+b \mu) t_{1}+\frac{b}{2} \mu^{2}\right\} \\
& +c I_{p}\left[\int_{\sigma}^{\mu} \mathrm{e}^{-\alpha t^{\beta}}\left\{\int_{t}^{\mu}(a+b s) \mathrm{e}^{\alpha s^{\beta}} \mathrm{d} s+\int_{\mu}^{t_{1}}(a+b \mu) \mathrm{e}^{\alpha s^{\beta}} \mathrm{d} s\right\} \mathrm{d} t\right. \\
& \left.\left.+\int_{\mu}^{t_{1}} \mathrm{e}^{-\alpha t^{\beta}}\left(\int_{t}^{t_{1}}(a+b \mu) \mathrm{e}^{\alpha s^{\beta}} \mathrm{d} s\right) \mathrm{d} t\right]-p I_{e} \int_{0}^{\sigma} t(a+b t) \mathrm{d} t\right] .
\end{aligned}
$$

Proof. For the above expression of TAC, the first order differential quotient of TAC $\left(t_{1}\right)$ with respect to $t_{1}$ is as follows

$$
\frac{d T A C\left(t_{1}\right)}{\mathrm{d} t_{1}}=\frac{(a+b \mu)}{T}\left[C_{1} \mathrm{e}^{\alpha t_{1}^{\beta}} \int_{0}^{t_{1}} \mathrm{e}^{-\alpha t^{\beta}} \mathrm{d} t+C_{3}\left(\mathrm{e}^{\alpha t_{1}^{\beta}}-1\right)-\frac{\left(C_{2}+C_{4} \delta\right)\left(T-t_{1}\right)}{1+\delta\left(T-t_{1}\right)}+c I_{p} \mathrm{e}^{\alpha t_{1}^{\beta}} \int_{\sigma}^{t_{1}} \mathrm{e}^{-\alpha t^{\beta}} \mathrm{d} t\right]
$$

The necessary condition for optimality of TAC, which is function of single variable only, yields the critical points from the equation (4.12).

Next, the auxiliary function of $\frac{\mathrm{dTAC}\left(t_{1}\right)}{\mathrm{d} t_{1}}$ is denoted by $f\left(t_{1}\right)$, where

$$
f\left(t_{1}\right)=C_{1} \mathrm{e}^{\alpha t_{1}^{\beta}} \int_{0}^{t_{1}} \mathrm{e}^{-\alpha t^{\beta}} \mathrm{d} t+C_{3}\left(\mathrm{e}^{\alpha t_{1}^{\beta}}-1\right)-\frac{\left(C_{2}+C_{4} \delta\right)\left(T-t_{1}\right)}{1+\delta\left(T-t_{1}\right)}+c I_{p} \mathrm{e}^{\alpha t_{1}^{\beta}} \int_{\sigma}^{t_{1}} \mathrm{e}^{-\alpha t^{\beta}} \mathrm{d} t .
$$

Then, the first order differential quotient of $f\left(t_{1}\right)$ with respect to $t_{1}$ is as follows

$$
\left.\frac{\mathrm{d} f\left(t_{1}\right)}{\mathrm{d} t_{1}}=\left[C_{1}\left(\alpha \beta t_{1}^{\beta-1} \mathrm{e}^{\alpha t_{1}^{\beta}} \int_{0}^{t_{1}} \mathrm{e}^{-\alpha t^{\beta}} \mathrm{d} t+1\right)+\frac{C_{2}+C_{4} \delta}{\left(1+\delta\left(T-t_{1}\right)\right)^{2}}+C_{3} \alpha \beta t_{1}^{\beta-1} \mathrm{e}^{\alpha t_{1}^{\beta}}+c I_{p}\left\{1+\alpha \beta t_{1}^{\beta-1} \mathrm{e}^{\alpha t_{1}^{\beta}} \int_{\sigma}^{t_{1}} \mathrm{e}^{-\alpha t^{\beta}} \mathrm{d} t\right]\right\}\right] .
$$

So, one can deduce the following relation $\frac{\mathrm{d}^{2} \mathrm{TAC}\left(t_{1}\right)}{\mathrm{d} t_{1}^{2}}=\frac{(a+b \mu)}{T} \frac{\mathrm{d} f\left(t_{1}\right)}{\mathrm{d} t_{1}}$, all of whose terms are positive in $0 \leq t_{1} \leq T$. Thus, $\frac{\mathrm{d}^{2} \mathrm{TAC}\left(t_{1}\right)}{\mathrm{d} t_{1}}$ is positive in $0 \leq t_{1} \leq T$, subject to following relation at the critical point $t_{1}=t_{1}^{*}$

$$
C_{1} \mathrm{e}^{\alpha t_{1}^{* \beta}} \int_{0}^{t_{1}^{*}} \mathrm{e}^{-\alpha t^{\beta}} \mathrm{d} t+C_{3}\left(\mathrm{e}^{\alpha t_{1}^{\beta}}-1\right)-\frac{\left(C_{2}+C_{4} \delta\right)\left(T-t_{1}^{*}\right)}{1+\delta\left(T-t_{1}^{*}\right)}+c I_{p} \mathrm{e}^{\alpha t_{1}^{* \beta}} \int_{\sigma}^{t_{1}^{*}} \mathrm{e}^{-\alpha t^{\beta}} \mathrm{d} t=0
$$

Hence the result. 


\section{Appendix C.}

Statement C.1. Deduce the optimality condition of TAC, where

$$
\begin{aligned}
\operatorname{TAC}\left(t_{1}\right)= & \frac{1}{T}\left[A+C_{1}\left\{\int_{0}^{\mu} \mathrm{e}^{-\alpha t^{\beta}}\left(\int_{t}^{\mu}(a+b s) \mathrm{e}^{\alpha s^{\beta}} \mathrm{d} s+\int_{\mu}^{t_{1}}(a+b \mu) \mathrm{e}^{\alpha s^{\beta}} \mathrm{d} s\right) \mathrm{d} t\right.\right. \\
& \left.+\int_{\mu}^{t_{1}} \mathrm{e}^{-\alpha t^{\beta}}\left(\int_{t}^{t_{1}}(a+b \mu) \mathrm{e}^{\alpha s^{\beta}} \mathrm{d} s\right) \mathrm{d} t\right\}+\left(C_{2}+C_{4} \delta\right)(a+b \mu) \int_{t_{1}}^{T} \frac{T-t}{1+\delta(T-t)} \mathrm{d} t \\
& +C_{3}\left\{\int_{0}^{\mu}(a+b t) \mathrm{e}^{\alpha t^{\beta}} \mathrm{d} t+\int_{\mu}^{t_{1}}(a+b \mu) \mathrm{e}^{\alpha t^{\beta}} \mathrm{d} t-(a+b \mu) t_{1}+\frac{b}{2} \mu^{2}\right\} \\
& \left.+c I_{p}\left\{\int_{\sigma}^{t_{1}} \mathrm{e}^{-\alpha t^{\beta}}\left(\int_{t}^{t_{1}}(a+b \mu) \mathrm{e}^{\alpha s^{\beta}} \mathrm{d} s\right) \mathrm{d} t\right\}-p I_{e}\left\{\int_{0}^{\mu} t(a+b t) \mathrm{d} t+\int_{\mu}^{\sigma} t(a+b \mu) \mathrm{d} t\right\}\right] .
\end{aligned}
$$

Proof. Analogous to Appendix B, the critical points from the equation (4.16) presents the optimality condition for TAC in $\mu<\sigma<t_{1}^{*}$ as follows

$$
C_{1} \mathrm{e}^{\alpha t_{1}^{* \beta}} \int_{0}^{t_{1}^{*}} \mathrm{e}^{-\alpha t^{\beta}} \mathrm{d} t+C_{3}\left(\mathrm{e}^{\alpha t_{1}^{* \beta}}-1\right)-\frac{\left(C_{2}+C_{4} \delta\right)\left(T-t_{1}^{*}\right)}{1+\delta\left(T-t_{1}^{*}\right)}+c I_{p} \mathrm{e}^{\alpha t_{1}^{* \beta}} \int_{\sigma}^{t_{1}^{*}} \mathrm{e}^{-\alpha t^{\beta}} \mathrm{d} t=0
$$

\section{Appendix D.}

Statement D.1. Deduce the optimality condition of TAC, where

$$
\begin{aligned}
\operatorname{TAC}\left(t_{1}\right)= & \frac{1}{T}\left[A+C_{1}\left\{\int_{0}^{\mu} \mathrm{e}^{-\alpha t^{\beta}}\left(\int_{t}^{\mu}(a+b t) \mathrm{e}^{\alpha t^{\beta}} \mathrm{d} t+\int_{\mu}^{t_{1}}(a+b \mu) \mathrm{e}^{\alpha t^{\beta}} \mathrm{d} t\right) \mathrm{d} t\right.\right. \\
& \left.+\int_{\mu}^{t_{1}} \mathrm{e}^{-\alpha t^{\beta}}\left(\int_{t}^{t_{1}}(a+b \mu) \mathrm{e}^{\alpha t^{\beta}} \mathrm{d} t\right) \mathrm{d} t\right\}+\left(C_{2}+C_{4} \delta\right)(a+b \mu) \int_{t_{1}}^{T} \frac{T-t}{1+\delta(T-t)} \mathrm{d} t \\
& +C_{3}\left\{\int_{0}^{\mu}(a+b t) \mathrm{e}^{\alpha t^{\beta}} \mathrm{d} t+\int_{\mu}^{t_{1}}(a+b \mu) \mathrm{e}^{\alpha t^{\beta}} \mathrm{d} t-(a+b \mu) t_{1}+\frac{b}{2} \mu^{2}\right\} \\
& \left.-p I_{e}\left\{(a+b \mu)\left(\sigma t_{1}-\frac{t_{1}^{2}}{2}\right)+\frac{b \mu^{2}}{2}\left(t_{1}-\sigma-\frac{\mu}{3}\right)\right\}\right]
\end{aligned}
$$

Proof. For the above expression of TAC, the first order differential quotient of $\mathrm{TAC}\left(t_{1}\right)$ with respect to $t_{1}$ is as follows

$$
\frac{\mathrm{dTAC}\left(t_{1}\right)}{\mathrm{d} t_{1}}=\frac{1}{T}\left[(a+b \mu)\left\{C_{1} \mathrm{e}^{\alpha t_{1}^{\beta}} \int_{0}^{t_{1}} \mathrm{e}^{-\alpha t^{\beta}} \mathrm{d} t+C_{3}\left(\mathrm{e}^{\alpha t_{1}^{\beta}}-1\right)-\frac{\left(C_{2}+C_{4} \delta\right)\left(T-t_{1}\right)}{1+\delta\left(T-t_{1}\right)}-p I_{e}\left(\sigma-t_{1}\right)\right\}-p I_{e} \frac{b}{2} \mu^{2}\right] .
$$

One can deduce the critical points, in which TAC is optimal from the equation (4.19). Next, second order differential quotient of $\operatorname{TAC}\left(t_{1}\right)$ with respect to $t_{1}$ is as follows

$$
\frac{\mathrm{d}^{2} \mathrm{TAC}\left(t_{1}\right)}{\mathrm{d} t_{1}^{2}}=\frac{(a+b \mu)}{T}\left[C_{1}\left(1+\alpha \beta t_{1}^{\beta-1} \mathrm{e}^{\alpha t_{1}^{\beta}} \int_{0}^{t_{1}} \mathrm{e}^{-\alpha t^{\beta}} \mathrm{d} t\right)+\frac{C_{2}+C_{4} \delta}{\left(1+\delta\left(T-t_{1}\right)\right)^{2}}+C_{3} \alpha \beta t_{1}^{\beta-1} \mathrm{e}^{\alpha t_{1}^{\beta}}+p I_{e}\right] .
$$


Since all terms of above expression are positive in $0 \leq t_{1} \leq T$, and $\frac{\mathrm{d}^{2} \mathrm{TAC}\left(t_{1}\right)}{\mathrm{d} t_{1}^{2}}$ is the sum of all these terms, the expression $\frac{\mathrm{d}^{2} \mathrm{TAC}\left(t_{1}\right)}{\mathrm{d} t_{1}^{2}}$ is positive in $0 \leq t_{1} \leq T$, subject to following relation at the critical point $t_{1}=t_{1}^{*}$

$$
(a+b \mu)\left\{C_{1} \mathrm{e}^{\alpha t_{1}^{* \beta}} \int_{0}^{t_{1}^{*}} \mathrm{e}^{-\alpha t^{\beta}} \mathrm{d} t+C_{3}\left(\mathrm{e}^{\alpha t_{1}^{* \beta}}-1\right)-\frac{\left(C_{2}+C_{4} \delta\right)\left(T-t_{1}^{*}\right)}{1+\delta\left(T-t_{1}^{*}\right)}-p I_{e}\left(\sigma-t_{1}^{*}\right)\right\}-p I_{e} \frac{b}{2} \mu^{2}=0 .
$$

Hence the result.

\section{REFERENCES}

[1] P. Aggrawal and T.J. Singh, An EOQ model with ramp type demand rate, time dependent deterioration rate and shortages. Glob. J. Pure Appl. Math. 13 (2017) 3381-3393.

[2] L.E.C. Barron, A.A. Shaikh. S. Tiwari and G.T. Garza, An EOQ inventory model with nonlinear stock dependent holding cost, nonlinear stock dependent demand and trade-credit. Comput. Ind. Eng. 139 (2020) 105557.

[3] A.K. Bhunia, C.K. Jaggi, A. Sharma and R. Sharma, A two-warehouse inventory model for deteriorating items under permissible delay in payment with partial backlogging. Appl. Math. Comput. 232 (2014) 1125-1137.

[4] D. Chakraborty, D.K. Jana and T.K. Roy, Two-warehouse partial backlogging inventory model with ramp type demand rate, three-parameter Weibull distribution deterioration under inflation and permissible delay in payments. Comput. Ind. Eng. 123 (2018) 157-179.

[5] H.J. Chang and C.Y. Dye, An inventory model for deteriorating items with partial backlogging and permissible delay in payments. Int. J. Syst. Sci. 32 (2001) 345-352.

[6] J. Chen, M. Dong, Y. Rong and L. Yang, Dynamic pricing for deteriorating products with menu cost. Omega 75 (2018) 13-26.

[7] L. Chen, X. Chen, M.F. Keblis and G. Li, Optimal pricing and replenishment policy for deteriorating inventory under stocklevel-dependent, time-varying and price-dependent demand. Comput. Ind. Eng. 135 (2018) 1294-1299.

[8] P. Chu, K.J. Chung and S.P. Lan, Economic order quantity of deteriorating items under permissible delay in payments. Comput. Oper. Res. 25 (1998) 817-824.

[9] K.J. Chung, S.L. Chang and W.D. Yang, The optimal cycle time for exponentially deteriorating products under trade-credit financing. Eng. Econ. 46 (2001) 232-242.

[10] R.P. Covert and G.C. Philip, An EOQ model for items with Weibull distribution deterioration. AIIE Trans. 5 (1973) $323-326$.

[11] B.C. Das, B. Das and S.K. Mondal, An integrated production-inventory model with defective item dependent stochastic credit period. Comput. Ind. Eng. 110 (2017) 255-263.

[12] B.K. Dey, B. Sarkar, M. Sarkar and S. Pareek, An integrated inventory model involving discrete setup cost reduction, variable safety factor, selling price dependent demand, and investment. RAIRO: OR 53 (2019) 39-57.

[13] A. Diabat, A.A. Taleizadeh, M. Lashgari, A lot sizing model with partial downstream delayed payment, partial upstream advance payment, and partial backordering for deteriorating items. J. Manuf. Syst. 45 (2017) 322-342.

[14] W.A. Donaldson, Inventory replenishment policy for a linear trend in demand. Oper. Res. Q. 28 (1977) 663-670.

[15] C.Y. Dye and C.T Yang, Optimal dynamic pricing and preservation technology investment for deteriorating products with reference price effects. Omega 62 (2016) 52-67.

[16] M. Ghandehari and M. Dezhtaherian, An EOQ model for deteriorating items with partial backlogging and financial considerations. Int. J. Serv. Oper. Manage. 32 (2019) 269-284.

[17] P.M. Ghare and G.F. Schrader, A model for an exponentially decaying inventory. J. Ind. Eng. 14 (1963) $238-243$.

[18] B.C. Giri, A.K. Jalan and K.S. Chaudhuri, Economic order quantity model with Weibull deterioration distribution, shortage and ramp-type demand. Int. J. Syst. Sci. 34 (2003) 237-243.

[19] S.K. Goyal, Economic order quantity under conditions of permissible delay in payments. J. Oper. Res. Soc. 36 (1985) $335-338$.

[20] F.M. Harris, How many parts to make at once. Fact. Mag. Manage. 10 (1913) 135-136.

[21] K.C. Hung, An inventory model with generalized type demand, deterioration and backorder rates. Eur. J. Oper. Res. 208 (2011) 239-242.

[22] C.K. Jaggi, L.E.C. Barron, S. Tiwari and A.A. Shafi, Two-warehouse inventory model for deteriorating items with imperfect quality under the conditions of permissible delay in payments. Sci. Iran. Trans. E Ind. Eng. 24 (2017) 390-412.

[23] C.K. Jaggi, V.S.S. Yadavalli, M. Verma and A. Sharma, An EOQ model with allowable shortage under trade-credit in different scenario. Appl. Math. Comput. 252 (2015) 541-551.

[24] A.M.M. Jamal, B.R. Sarker and S. Wang, An ordering policy for deteriorating items with allowable shortage and permissible delay in payment. J. Oper. Res. Soc. 48 (1997) 826-833.

[25] R. KavithaPriya and K. Senbagam, An EOQ inventory model for two parameter weibull deterioration with quadratic time dependent demand and shortages. Int. J. Pure Appl. Math. 119 (2018) 467-478.

[26] S. Khanra, S.K. Ghosh and K.S. Chaudhuri, An EOQ model for a deteriorating item with time dependent quadratic demand under permissible delay in payment. Appl. Math. Comput. 218 (2011) 1-9.

[27] M.S. Kim and B. Sarkar, Multi-stage cleaner production process with quality improvement and lead time dependent ordering cost. J. Clean Prod. 144 (2016) 572-590. 
[28] M. Lashgari, A.A. Taleizadeh and S.S. Sana, An inventory control problem for deteriorating items with backordering and financial considerations under two levels of trade-credit linked to order quantity. J. Ind. Manage. Optim. 12 (2016) 1091-1119.

[29] J. Li, H. Feng and Y. Zeng, Inventory games with permissible delay in payments. Eur. J. Oper. Res. 234 (2014) $694-700$.

[30] J. Lin, A demand independent inventory model. Yugosl. J. Oper. Res. 23 (2013) 129-135.

[31] A. Mahmoodi, Joint pricing and inventory control of duopoly retailers with deteriorating items and linear demand. Comput. Ind. Eng. 132 (2019) 36-46.

[32] B. Mandal and A.K. Pal, Order level inventory system with ramp type demand rate for deteriorating items. J. Interdiscip. Math. 1 (1998) 49-66.

[33] A.H. Mashud, M.A. Khan, M.S. Uddin and M.N. Islam, A non-instantaneous inventory model having different deterioration rates with stock and price dependent demand under partially backlogged shortages. Uncertain Supply Chain Manage. 6 (2018) 49-64.

[34] J. Min, Y. Zhou, G.Q. Liu and S.D. Wang, An EPQ model for deteriorating items with inventory level-dependent demand and permissible delay in payments. Int. J. Syst. Sci. 43 (2012) 1039-1053.

[35] U. Mishra, An EOQ model with time dependent Weibull deterioration, quadratic demand and partial backlogging. Int. J. Appl. Comput. Math. 2 (2016) 545-563.

[36] I. Moon, E. Shin and B. Sarkar, Min-max distribution free continuous-review model with a service level constraint and variable lead time. Appl. Math. Comput. 229 (2014) 310-315.

[37] A. Mukhopadhyay and A. Goswami, An EOQ model with shortages and selling price dependent time varying demand. Int. J. Supply Chain Inventory Manage. 1 (2016) 133-153.

[38] B. Pal, Optimal production model with quality sensitive market demand, partial backlogging and permissible delay in payment. RAIRO: OR 52 (2018) 499-512.

[39] V. Pando, L.A. San-Jose and J. Sicilia, Profitability ratio maximization in an inventory model with stock-dependent demand rate and non-linear holding cost. Appl. Math. Model. 66 (2018) 643-661

[40] V. Pando, L.A. San-Jose, J.G. Laguna and J. Sicilia, Optimal lot-size policy for deteriorating items with stock-dependent demand considering profit maximization. Comput. Ind. Eng. 117 (2018) 81-93.

[41] S. Papachristos and K. Skouri, An optimal replenishment policy for deteriorating items with time-varying demand and partial exponential type backlogging. Oper. Res. Lett. 27(4) (2000) 175-184.

[42] M. Pervin, S.K. Roy and G.W. Weber, Analysis of inventory control model with shortage under time dependent demand and time-varying holding cost including stochastic deterioration. Ann. Oper. Res. 260 (2018) 437-460.

[43] Y. Qiu, J. Qiao and P.M. Pardalos, Optimal production, replenishment, delivery, routing and inventory management policies for products with perishable inventory. Omega 82 (2019) 193-204.

[44] R.S. Rajan and R. Uthayakumar, Analysis and optimization of an EOQ inventory model with promotional efforts and backordering under delay in payments. J. Manage. Anal. 4 (2017) 159-181.

[45] L.A. San-Jose, J. Sicilia and D.A.L. Pablo, An inventory system with demand dependent on both time and price assuming backlogged shortages. Eur. J. Oper. Res. 270 (2018) 889-897.

[46] L.A. San-Jose, J. Sicilia, L.E.C. Barronz and J.M. Gutierrezx, Optimal price and quantity under power demand pattern and non-linear holding cost. Comput. Ind. Eng. 129 (2019) 426-434.

[47] B. Sarkar, An EOQ model with delay in payments and time varying deterioration rate. Math. Comput. Model. 55 (2012) $367-377$.

[48] B. Sarkar, Supply chain coordination with variable backorder, inspections, and discount policy for fixed lifetime products. Math. Prob. Eng. 2016 (2016) 14.

[49] B. Sarkar, Mathematical and analytical approach for the management of defective items in a multi-stage production system. J. Clean Prod. 218 (2019) 896-919.

[50] B. Sarkar and S. Sarkar, An improved inventory model with partial backlogging, time varying deterioration and stock-dependent demand. Econ. Model. 30 (2013) 924-932.

[51] B. Sarkar, L.E.C. Barron, M. Sarkar and M.L. Singgih, An economic production quantity model with random defective rate, rework process and backorders for a single stage production system. J. Manuf. Syst. 33 (2014) 423-435.

[52] B. Sarkar, H. Gupta, K. Chaudhuri and S.K. Goyal, An integrated inventory model with variable lead time, defective units and delay in payments. Appl. Math. Comput. 237 (2014) 650-658.

[53] B. Sarkar, S. Saren and H. M. Wee, An inventory model with variable demand, component cost and selling price for deteriorating items. Econ. Model. 30 (2013) 306-310.

[54] B. Sarkar, S. Saren, D. Sinha and S. Hur, Effect of unequal lot sizes, variable setup cost, and carbon emission cost in a supply chain model. 2015 (2015) 469486.

[55] D. Seifert, R.W. Seifert and O.H.D. Isaksson, A test of inventory models with permissible delay in payment. Int. J. Prod. Res. 55 (2017) 1117-1128.

[56] N. Sen and S. Saha, An inventory model for deteriorating items with time dependent holding cost and shortages under permissible delay in payment. Int. J. Procure. Manage. 11 (2018) 518-531.

[57] A.A. Shaikh, G.C. Panda, S. Sahu and A.K. Das, Economic order quantity model for deteriorating item with preservation technology in time dependent demand with partial backlogging and trade-credit. Int. J. Logist. Syst. Manage. 32 (2019) $528-542$.

[58] Y. Shi, Z. Zhang, F. Zhou and Y. Shi, Optimal ordering policies for a single deteriorating item with ramp-type demand rate under permissible delay in payments. J. Oper. Res. Soc. 70 (2019) 1848-1868. 
[59] S.W. Shinn, H. Hwang and S.S. Park, Joint price and lot size determination under conditions of permissible delay in payments and quantity discounts for freight cost. Eur. J. Oper. Res. 91 (1996) 528-542.

[60] E.A. Silver and H.C. Meal, A heuristic for selecting lot size requirements for the case of a deterministic time varying demand rate and discrete opportunities for replenishment. Prod. Inventory Manage. 14 (1973) 64-74.

[61] T. Singh and H. Pattanayak, An EOQ model for a deteriorating item with time dependent quadratic demand and variable deterioration under permissible delay in payment. Appl. Math. Sci. 59 (2013) 2939-2951.

[62] T. Singh, P.J. Mishra and H. Pattanayak, An EOQ inventory model for deteriorating items with time-dependent deterioration rate, ramp-type demand rate and shortages. Glob. J. Pure Appl. Math. 12 (2018) 423-437.

[63] K. Skouri, An EOQ model with backlog-dependent demand. Oper. Res. Int. J. 18 (2018) 561-574.

[64] K. Skouri, I. Konstantaras, S. Papachristos and I. Ganas, Inventory models with ramp type demand rate, partial backlogging and Weibull deterioration rate. Eur. J. Oper. Res. 192 (2009) 79-92.

[65] A.A. Taleizadeh and M. Nematollahi, An inventory control problem for deteriorating items with backordering and financial considerations. Appl. Math. Model. 38 (2014) 93-109.

[66] A.A. Taleizadeh, D. Pentico, M.S. Jabalame and M. Aryanezhad, An EOQ model with partial delayed payment and partial backordering. Omega 41 (2013) 354-368.

[67] M. Tayyab and B. Sarkar, Optimal batch quantity in a cleaner multi-stage lean production system with random defective rate. J. Clean Prod. 139 (2016) 922-934.

[68] Vandana and B.K. Sharma, An EOQ model for retailers partial permissible delay in payment linked to order quantity with shortages. Math. Comput. Simul. 125 (2016) 99-112.

[69] R.H. Wilson, A scientific routine for stock control. Harv. Bus. Rev. 13 (1934) 116-128.

[70] K.S. Wu, An EOQ inventory model for items with weibull distribution deterioration, ramp type demand rate and partial backlogging. Prod. Plan. Control Manage. Oper. 12 (2001) 787-793.

[71] K.S. Wu, L.Y. Ouyang and C.T. Yang, An optimal replenishment policy for non-instantaneous deteriorating items with stockdependent demand and partial backlogging. Int. J. Prod. Econ. 101 (2006) 369-384.

[72] J. Wu, K. Skouri, J.T. Teng and Y. Hu, Two inventory systems with trapezoidal-type demand rate and time-dependent deterioration and backlogging. Expert Syst. Appl. 46 (2016) 367-379.

[73] J.W. Wu, L. Chinho, B. Tan and W.C. Lee, An EOQ inventory model with ramp type demand rate for items with Weibull deterioration. Int. J. Inf. Manage. Sci. 10 (1999) 41-51. 